\title{
How Many Replicators Does It Take to Achieve Reliability? Investigating Researcher Variability in a Crowdsourced Replication ${ }^{1}$
}

\author{
Version 23-Feb-2022
}

Principal investigators:

Nate Breznau, Eike Mark Rinke and Alexander Wuttke

Participant replicators:

Muna Adem, Jule Adriaans, Esra Akdeniz, Amalia Alvarez-Benjumea, Henrik Andersen, Daniel Auer, Flavio Azevedo, Oke Bahnsen, Ling Bai, Dave Balzer, Paul C. Bauer, Gerrit Bauer, Markus Baumann, Sharon Baute, Verena Benoit, Julian Bernauer, Carl Berning, Anna Berthold, Felix S. Bethke, Thomas Biegert, Katharina Blinzler, Johannes N. Blumenberg, Licia Bobzien, Andrea Bohman, Thijs Bol, Amie Bostic, Zuzanna Brzozowska, Katharina Burgdorf, Kaspar Burger, Kathrin Busch, Juan Castillo, Nathan Chan, Pablo Christmann, Roxanne Connelly, Christian Czymara, Elena Damian, Eline de Rooij, Alejandro Ecker, Achim Edelmann, Christine Eder, Maureen A. Eger, Simon Ellerbrock, Anna Forke, Andrea Forster, Danilo Freire, Chris Gaasendam, Konstantin Gavras, Vernon Gayle, Theresa Gessler, Timo Gnambs, Amélie Godefroidt, Max Grömping, Martin Groß, Stefan Gruber, Tobias Gummer, Andreas Hadjar, Verena Halbherr, Jan Paul Heisig, Sebastian Hellmeier, Stefanie Heyne, Magdalena Hirsch, Mikael Hjerm, Oshrat Hochman, Jan H. Höffler, Andreas Hövermann, Sophia Hunger, Christian Hunkler, Nora Huth, Zsofia Ignacz, Sabine Israel, Laura Jacobs, Jannes Jacobsen, Bastian Jaeger, Sebastian Jungkunz, Nils Jungmann, Jennifer Kanjana, Mathias Kauff, Sayak KhatuaManuel Kleinert, Julia Klinger, Jan-Philipp Kolb, Marta Kołczyńska, John Kuk, Katharina Kunißen, Jennifer Kanjana, Salman Khan, Dafina Kurti, Alexander Langenkamp, Robin Lee, David Liu, Philipp Lersch, Lea-Maria Löbel, Philipp Lutscher, Matthias Mader, Joan Madia, Natalia Malancu, Luis Maldonado, Helge Marahrens, Nicole Martin, Paul Martinez, Jochen Mayerl, Oscar J. Mayorga, Robert McDonnell, Patricia McManus, Kyle McWagner, Cecil Meeusen, Daniel Meierrieks, Jonathan Mellon, Friedolin Merhout, Samuel Merk, Daniel Meyer, Jonathan Mijs, Cristobal Moya, Marcel Neunhoeffer, Daniel Nüst, Olav Nygård, Fabian Ochsenfeld, Gunnar Otte, Anna Pechenkina, Mark Pickup, Christopher Prosser, Louis Raes, Kevin Ralston, Miguel Ramos, Frank Reichert, Leticia Rettore Micheli, Arne Roets, Jonathan Rogers, Guido Ropers, Robin Samuel, Gregor Sand, Constanza Sanhueza Petrarca, Ariela Schachter, Merlin Schaeffer, David Schieferdecker, Elmar Schlueter, Katja Schmidt, Regine Schmidt, Alexander Schmidt-Catran, Claudia Schmiedeberg, Jürgen Schneider, Martijn Schoonvelde, Julia Schulte-Cloos, Sandy Schumann, Reinhard Schunck, Jürgen Schupp, Julian Seuring, Henning Silber, Willem Sleegers, Nico Sonntag, Alexander Staudt, Nadia Steiber, Nils Steiner, Sebastian Sternberg, Dieter Stiers, Dragana Stojmenovska, Nora Storz, Erich Striessnig, Anne-Kathrin Stroppe, Jordan W Suchow, Janna Teltemann, Andrey Tibajev, Brian Tung, Giacomo Vagni, Jasper Van Assche, Meta van der Linden, Jolanda van der Noll, Arno Van Hootegem, Stefan Vogtenhuber, Bogdan Voicu, Fieke Wagemans, Nadja Wehl, Hannah Werner, Brenton Wiernik, Fabian Winter, Christof Wolf, Cary Wu, Yuki Yamada, Nan Zhang, Conrad Ziller, Björn Zakula, Stefan Zins, Tomasz Żółtak

Primary authorship and contact:

Nate Breznau, University of Bremen breznau.nate@gmail.com

(iD) 0000-0003-4983-3137

Data assistance:

Hung H.V. Nguyen

\footnotetext{
${ }^{1}$ This research in this paper is partly funded by the Deutsche Forschungsgemeinschaft (DFG, German Research Foundation) Special Priority Program project "The Role of Theory in Resolving the Reproducibility Crisis" at the University of Bremen, project number 464546557.
} 


\section{AbStract}

This paper reports findings from a crowdsourced replication. Eighty-five independent teams attempted a computational replication of results reported in an original study of policy preferences and immigration by fitting the same statistical models to the same data. The replication involved an experimental condition. Random assignment put participating teams into either the transparent group that received the original study and code, or the opaque group receiving only a methods section, rough results description and no code. The transparent group mostly verified the numerical results of the original study with the same sign and p-value threshold (95.7\%), while the opaque group had less success (89.3\%). Exact numerical reproductions to the second decimal place were far less common $(76.9 \%$ and $48.1 \%)$, and the number of teams who verified at least $95 \%$ of all effects in all models they ran was $79.5 \%$ and $65.2 \%$ respectively. Therefore, the reliability we quantify depends on how reliability is defined, but most definitions suggest it would take a minimum of three independent replications to achieve reliability. Qualitative investigation of the teams' workflows reveals many causes of error including mistakes and procedural variations. Although minor error across researchers is not surprising, we show this occurs where it is least expected in the case of computational reproduction. Even when we curate the results to boost ecological validity, the error remains large enough to undermine reliability between researchers to some extent. The presence of inter-researcher variability may explain some of the current "reliability crisis" in the social sciences because it may be undetected in all forms of research involving data analysis. The obvious implication of our study is more transparency. Broader implications are that researcher variability adds an additional meta-source of error that may not derive from conscious measurement or modeling decisions, and that replications cannot alone resolve this type of uncertainty. 


\section{INTRODUCTION}

The credibility of science relies on the replicability of research findings. If different researchers testing the same hypothesis come to similar results within an acceptable margin of error, then the hypothesis becomes a sturdy building block for theoretical knowledge. Recent evidence suggests that research on complex behavioral and social phenomenon may be less reliable than academics might hope. This is blatantly obvious in 'many analyst' studies where different researchers attempting to test the same hypotheses with identical data, come to wildly different results (Botvinik-Nezer et al. 2020; Breznau et al. 2021; Schweinsberg et al. 2021; Silberzahn et al. 2018). Outcome variability has many potential sources. Analytic flexibility is often cited for causing reliability issues (Gelman and Loken 2014; Wicherts et al. 2016; Young 2018). Moreover, intentional p-hacking, HARKing and in rare cases fraud are also seen as highly problematic (Breznau 2021; Head et al. 2015; Nosek, Spies, and Motyl 2012; Pickett 2020). Leaving aside unethical or negatively incentivized practices, researchers sometimes simply make mistakes while preparing data or running analyses (Herndon, Ash, and Pollin 2013; Jasso 1986). Less attention is paid less to procedural or more mundane aspects of research such as software, data storage formats, routines or version control (Breznau 2016; McCoach et al. 2018). When there are so many sources of error across researchers, we should not be surprised that studies often fail to replicate. The replications themselves after all are subject to many of the same sources of error as an original study.

There is one type of research that should be an exception. The case of computational reproduction is special in the sense that it should involve decision-making and thus it should have no 'garden of forking paths' or analytic flexibility to lead researchers to different results. Therefore, when researches fit the same models and data we expect no result variation unless of course the original study included mistakes or reporting errors (Freese and Peterson 2017). Any researcher with the relevant methodological skills should be able to verify another's results. Yet recent evidence suggests even computational reproductions are unreliable. This was dramatically brought to light when the American Journal of Political Science started checking the reproducibility of all quantitative research results in papers accepted for publication. The first 15 studies' results could not be verified, and in the first year it took an average of 1.7 communications per accepted manuscript before the authors' results could be reproduced (Jacoby, Lafferty-Hess, and Christian 2017; Janz 2015). These are not exceptional cases. Hardwicke et al. (2018) met similar challenges when they attempted to verify the results of studies published in the journal Cognition and found that, even with author assistance, $37 \%$ of the articles (13-of-35) had at least one effect that could not be statistically reproduced within $10 \%$ of the original. Similarly, Stockemer et al. (2018) failed to reproduce one-third of the results among major political behavior publications in 2015. Even more troubling was that for onequarter they could not produce any numerical results because the code was so poorly organized. These and 
other studies suggest that even basic 'copy-paste' research is prone to variability in outcomes (see also Eubank 2016). If computational reproduction is unreliable at the inter-researcher-level, this may offer unique insight into reliability in other types of replications and research in general.

Let us assume that if at least $95 \%$ of a population of researchers would come to correct numerical results, then the research is reliable. If less than $95 \%$ of a potential researcher population would arrive at correct results, then it would require more than one replication to achieve a cumulative probability that a majority of replicators arrive at the correct verification at least $95 \%$ of the time. To demonstrate when more than one replication would be necessary, we plot a simulation based on binomial probabilities of researchers coming to a correct computational replication. In real-world research we do not know in advance what is 'correct' or 'true', as this would undermine the need to conduct research in the first place. This is again why computational reproduction is such an important case, because we can know the correct result in advance at least within a degree of rounding error. To measure a majority in our simulation, we start with a calculation of $51 \%$ of $n$ replications arriving at $x$, the correct answer. Thus in one replication, $x$ must be equal to 1 ; in two replications $x=2$; in three replications $x \geq 2$; in four replications $x \geq 3$ and so forth. We can then calculate the probability $P$ of arriving at $x$ successful outcomes among $n$ replications when the true likelihood of a successful replication is $p$ using the Bernoulli trials formula $P(X \geq x)=f(x)=$ $\left(\begin{array}{l}n \\ x\end{array}\right) p^{x}(1-p)^{n-x}$. Then we can calculate the minimum value of $n$ for our critical threshold of $\mathrm{P}=0.95$ (i.e., $95 \%$ confidence), and this gives us the answer to how many independent replications it takes to achieve reliability at different theoretical values of $p$ replicability.

Figure 1 presents different values of $n$ at theoretical values of $p$ at different $\mathrm{P}$ thresholds. 
Figure 1. Number of Independent Replications to Achieve Reliability by Confidence Threshold

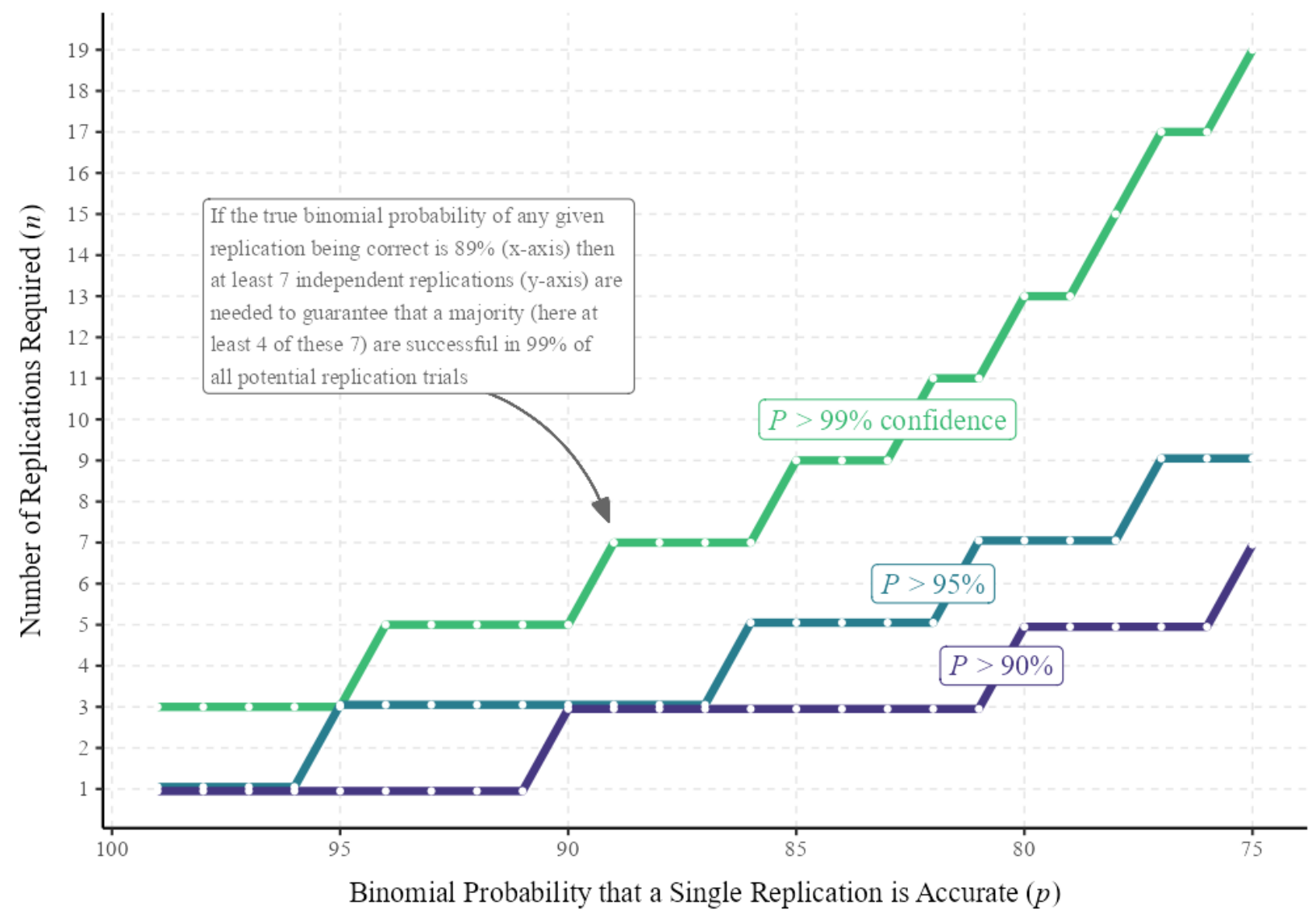

Figure 1 is a simulation, and $p$ is an unknown property of computational reproductions that we aim to identify in this article. We use the term researcher variability to suggest that different researchers doing the same research will have different results to some degree. Not just because they make mistakes or lack transparent and well-documented materials, but for a range of idiosyncratic and procedural features of the researchers and their workflows.

\section{A Crowdsourced Replication to Measure Researcher Variability}

To test how much variability occurs in research ostensibly free of analytic decision-making, and how much of this variability is due to the transparency and quality of the original study's materials, we launched a Crowdsourced Replication Initiative (CRI) in 2018 (Breznau, Rinke and Wuttke 2019). The first phase collected a pool of researchers and observed them as they attempted to verify a study's previously published numerical results. In the CRI, we elected to replicate David Brady and Ryan Finnigan's (2014) American Sociological Review study, “Does Immigration Undermine Public Support for Social Policy?”. This original study met several ideal criteria: highly cited, freely available data and code, independently 
verifiable by two of the CRI's principal investigators and the original authors were comfortable with their work being the target. The Brady and Finnigan study used two waves of International Social Survey Program (ISSP) data with questions about attitudes towards the government's responsibility to provide various forms of social welfare and security. The original study aggregated responses to these questions and regressed them on stock and flow of immigration measures at the country-level across different model specifications including social spending and employment rate as independent variables.

Prior to conducting the CRI, we preregistered our replication experiment on the Open Science Framework including a power analysis that helped us determine that we needed at least 60 replicator teams to introduce an experimental design (Breznau, Rinke and Wuttke 2018). We had 105 teams with a maximum of three researchers each register initially, and 99 successfully completed the first CRI task which was to respond to a survey. Random assignment of the original 99 teams placed 50 into a transparent group (TG) that received the Brady and Finnigan article, the Stata code and their published technical appendix. This group had theoretically no research design decisions to make, just verify the original study following their methods and code. The other 49 teams, the opaque group (OG), got an anonymized and far less transparent version of the study. Comparison of means for team features across groups reveals successful random assignment (see Table 1 in Appendix B). Thirteen teams dropped out before starting the replication and one during the replication leaving 39 teams in the TG and 46 in the OG. All materials that can be shared publicly are in our Project Repository ${ }^{2}$.

To create a non-transparent condition of the study for the OG to replicate, the PIs altered the Brady and Finnigan study so that it included models testing only 4-out-of- 6 of the dependent variables, an analysis without the individual-level income variable (selected for removal because it had almost no impact on any effects) and, instead of the full paper, a Methods Section written by the PIs describing the models, and direction and significance of coefficients without any numbers and without code (see Appendix A.3). Our two experimental conditions were intended to simulate polar extremes in the transparency of a secondary data analysis in social science. For the purposes of simulating a real research endeavor, the participants were instructed to use the software they normally conducted their research with, rather than learn Stata. In the TG the Stata users were asked to write their own code rather than simply run the file from the original authors.

Participants had three weeks to complete the replication, with extensions granted upon request. Participants were asked to present odds ratios as these were the numerical outcomes reported in the original study. All teams received an Excel template for reporting these odds ratios and coefficient p-values to help standardize reporting. We recorded teams' numerical reproductions of four dependent variables modeled

\footnotetext{
${ }^{2}$ GitHub repo https://github.com/nbreznau/how_many_replicators
} 
with different covariates in a total of 26 models (the first four columns of Brady and Finnigan 2014: Tables $4 \& 5^{3}$ ). Four models included both stock and flow measures of immigration (percent foreign-born and net migration) but these were not given to the OG in another step to disguise the original study. Thus, a total of 48 odds ratios in the TG and 40 in the OG were reported for analysis. A few models ran into nonconvergence problems and a few teams made mistakes, therefore not all reported all effects. The final $\mathrm{N}$ was 3,695 odds ratios from 85 teams.

Not all CRI participants consented to sharing their replication code non-anonymously, given that it might show differences in skills and reveal mistakes. This was partly a product of our research design: we did not engage in quality control or provide workflow guidance other than the template for reporting results. Some submitted in Word or RTF document formats and others used German-language Excel with commas instead of decimal places. This meant that we had to construct a matrix of all results with some copy-pasting from the various file formats. This meant we triple checked (and then again checked during the peer review process) that their submitted code produced these results. In four teams, parts of the code were missing due to a point-and-click method or researchers not saving their workflows ${ }^{4}$. To incur minimal ecological bias, we did not offer extra opportunities for teams to update or fix their mistakes, we simply took the results as they were. Starting with the teams' submitted workflows and results, all of the proceeding work where we analyze data, produce figures and utilize a participant survey are available in our Project Repository. In order to determine the sources of researcher variability we qualitatively investigated the content of each team's workflow. We provide redacted code from each team in Appendix C.

It is arguable, that more errors would occur in this work than real-world research where the stakes are higher. Thus, to offer a second version of ecological validity for our study we curated the work to generate a second set of results that was free from mistakes where possible. We attempted to fix mistakes in the teams' code if two conditions were met: It had to be obvious that it was a mistake and, if so, that we could determine a counterfactual scenario of what the authors would have done instead. We corrected code in 14 instances in 12 teams' workflows. This left us with a set of curated results that might have greater ecological validity given that we had no peer review process and the teams were not engaging in 'primary' research that would lead to their own publication.

We only changed code when we did not have to make any decisions. For example, if a team omitted a 'fixed-effect' for country or year, we corrected this. If a team forgot to include a country or added an extra country into the original sample, we adjusted it. However, if we had to make recoding decisions that could have played out in complex ways, like how to standardize variables or combine categories of employment

\footnotetext{
${ }^{3}$ Readers can view these original tables in our workflow file 01_Data_Prep.Rmd.

${ }^{4}$ In two cases further exchanges with the teams were necessary to get their code running because it contained procedural elements the PIs were not familiar with - once in an R project and another running MLwiN in a Stata shell.
} 
or education, we did not correct anything. It was theoretically possible to eliminate all sources of deviation from the original results except for missing code cases and two where we did not find the exact source of minor deviations within three hours, a timeframe we decided to introduce as a cutoff. We also left the code completely as it was if the verification rate for that team was higher than $95 \%$.

Verifiability via replication, also known as a computational reproduction in some literatures, means producing the same results as the original study using the same data and code (Freese and Peterson 2017:152-53). Unfortunately, there are no standards for what constitutes "same results". The naïve onlooker should expect results to match exactly. This is not the case. Reporting at different decimal places, usage of different data storage file types and different software read/write procedures introduces minute errors. Therefore, we define three reproducibility measures. Two are dichotomous variables, a Verification is when the results point in the same direction and match a null hypothesis significance test that the coefficient is exactly zero with a cut-off of $\mathrm{p}<0.05$, and an Exact Replication is when it matches the original within two decimal places $(<0.01)$. The third was a continuous variable Replication Error measured as the absolute value of the difference between the estimated odds ratio and original. Descriptive statistics of these measures are presented in Table 1 in Appendix B and visualized in Figure 2.

Using the results from our participant survey, we constructed variables for the discipline of the replicator team. In 82 of 85 teams, there was a majority discipline. For the remaining three teams we took the discipline of the first team member - the initial responder to the call and the person responsible for organizing the team. We collapsed this into a variable labeled Sociology where sociology degrees $=1(43$ teams) and other disciplines $=0$ which were mostly political science (22) teams and others (like psychology, communications, methods-focused-degrees and economics). We measured a continuous variable Stats-Skill as a latent factor from 4 questions on team members' reported experience with statistics ${ }^{5}$. We created a variable from one question called Difficult ranging from 0 to 5, from lowest to highest subjective difficulty. Finally, we coded statistical software as Stata $=1$ (56 teams) versus other software $(=0$; where 22 used R, 4 used SPSS and 3 used Mplus).

\section{RESULTS}

Reproduction results appear in Figure 2 with further descriptive statistics in Table 1 in Appendix B. Panel A of Figure 2 shows the percentage of all effects that were a Verification and an Exact Replication by group assignment, and then the average Replication Error. These results are separated into 'Raw' and 'Curated'. Panel B presents team-level results. Rather than take the mean of a dichotomous concept for Verification and Exact Replication at the team-level, we instead code a "1" if 95\% or more of all within-

\footnotetext{
${ }^{5}$ See confirmatory factor analysis in Project Repository.
} 
team effects scored "1" (=Verification at effect-level). For Replication Error, it is the average of the teamaverage Error.

The raw effect-level results indicate a high degree of reproducibility. The numerical results of the original study were verified in 95.7 and $89.3 \%$ of the TG and OG replications respectively. After curation these rates jumped to 98.2 and $92.3 \%$. When pooled, this means $92.5 \%$ verification rate of the raw results, but $95.2 \%$ of the curated results - a value above a common threshold of reliability. The numbers drop for Exact Replications, where even the pooled curated results do not make this $95 \%$ cutoff. Only $70.2 \%$ of all replications were identical to the second decimal place $(<0.01)$; even in the best-case-scenario, with fully transparent materials, only $83.9 \%$ arrived at exact results. At the team-level the reproducibility rates are all below $95 \%$. Only $79.5 \%$ of teams in the TG had complete Verification $(95 \%+$ of all within-team effects verified) across their 48 reported effects and only $62.5 \%$ of the teams in the OG had this across their 40 reported effects. The curated results are only slightly higher for both groups. The difference between experimental groups at the team-level increases dramatically for Exact Replication where $61.5 \%$ of the TG had at least $95 \%$ of their effects within 0.01 of the original but only $6.5 \%$ of teams in the OG; in other words, only 3 out of 46 OG teams reproduced the results unanimously.

The far-right column of Figure 2.B offers a decomposition of variance $\left(\sigma^{2}\right)$ allowing us to see that a great deal of variance occurs between teams rather than within teams, based on the intra-class correlation as a percentage score. For the curated results of the TG and Verifications it is as high as $90 \%$. This drops when measuring Exact Replications. We notice that teams with a perfect Verification rate often have several effects that fall just outside of the 0.01 cutoff that we defined for Exact Replications. However, this varies dramatically by group. The TG had less than or roughly half of the total variance occurring between-teams for Exact Replications, while the OG was near $70 \%$ for Exact Replications.

It would appear that the additional layer of curation did not substantially improve between-team rates of replication, at least not in a way that would allow us to conclude it exceeds a high bar for reliability. What we can clearly conclude on the meta-level is that the bulk of reproduction failure occurs between teams. Researchers make less errors in isolation, and instead more often make repeated errors across models. We concede that an incorrectly modeled effect could still randomly verify the original (same sign/significance) so we should not expect verification rates close to zero even if all their models contain error. Alternatively, when looking at Replication Error, there is more variance within-teams in both groups and in both conditions. This means that numerical errors at a very high level of accuracy, occur in many teams and can occur in isolation within a team, unique to a model. In sum, verifications are relatively consistent whereas more precise numerical error occurs more randomly, or at least needs further explanation (an issue to which we turn our attention in the section Decomposition of Error). 
Figure 2. Results of a Crowdsourced Replication from 85 Replicator Teams

A. Effect-Level Results, $\mathrm{N}=3,742$
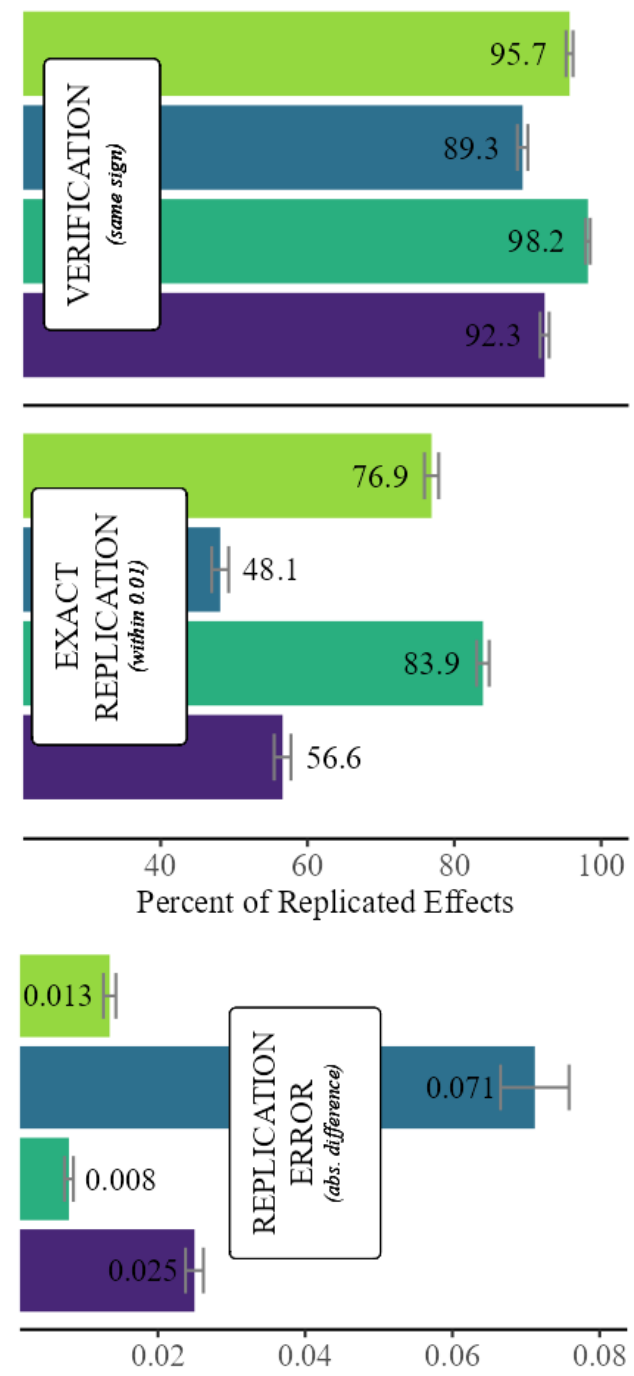

Absolute Difference from Original Effect
B. Team-Level Results, $\mathrm{N}=85$

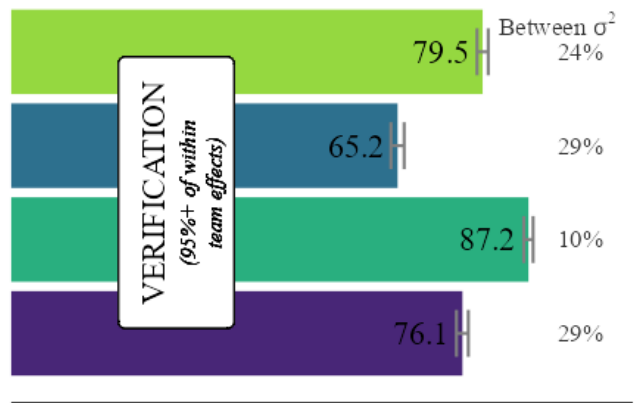

\section{CURATED}

Transparent

CURATED

Opaque

Group

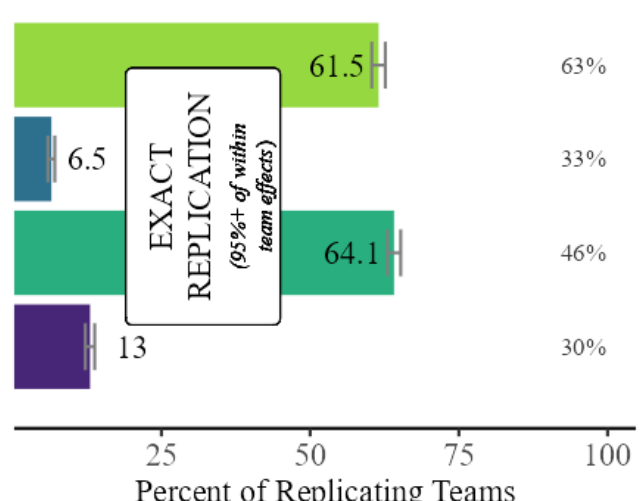

Percent of Replicating Teams

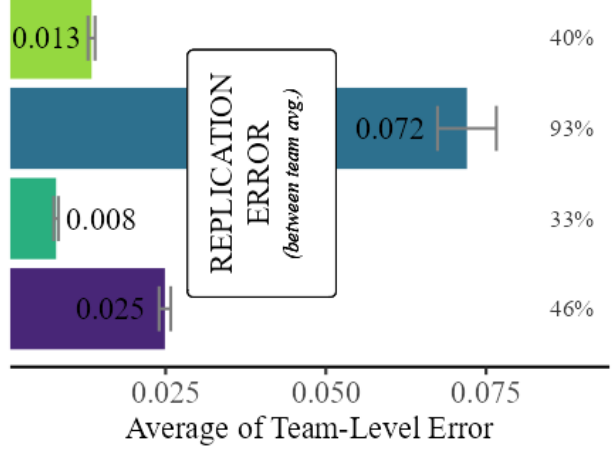

NOTE: Transparent group (TG) had 39 teams and the opaque group (OG) had 46. The replicator teams attempted to reproduce results from Brady and Finnigan (2014); however, the OG had an anonymized version with only a Methods Section and no code (see Section 2 and Appendix A for experiment details). 


\section{Sources of Error and Curation}

We investigated the sources of researcher variability by qualitatively analyzing the content of each team's code and any comments they provided. This activity also allowed us to perform our curation. Prior to the study the PIs preregistered a theoretical set of categories that might be sources of error (see Table 1 in Breznau, Rinke and Wuttke 2018); however, grounded in the content and based on the PI's knowledge of quantitative research and statistical programming a total of six coding categories emerged, not all were anticipated at the time of preregistration: Mistake, Procedural, Mistake-Procedural, Missing Component, Interpretational and Questionable Method Knowledge. We present the definitions for each category with selected examples in the following. A summary of all teams and their category codes is available in Table 5 (in Appendix B), and again all redacted code in Appendix C.

Mistake (29 instances in 24 teams)

These are steps that teams did not intent to take. Nearly all are coding errors, for example copypasting the same code snippet over and over and forgetting to alter the variable name, reversing the wave values (1996 instead of 2006), mistakenly recoding all values in a dependent variable to zeros, forgetting variables in the analysis and including the wrong countries in the sample. A few were clerical errors where teams reported coefficients instead of odds ratios or pasted the wrong set of results into the result template. 
Table 2. Selected examples of mistakes and curations

\begin{tabular}{|c|c|c|}
\hline Team & Original & Curation \\
\hline \multirow[t]{2}{*}{$\begin{array}{c}5 \\
(\text { Stata })\end{array}$} & $\begin{array}{l}\text { use ZA2900.dta, clear } \\
\text { gen year }=\mathbf{2 0 0 6}\end{array}$ & $\begin{array}{l}\text { use ZA2900.dta, clear } \\
\text { gen year = } 1996\end{array}$ \\
\hline & $\begin{array}{l}\text { use ZA4700.dta, clear } \\
\text { gen year }=1996\end{array}$ & $\begin{array}{l}\text { use ZA } 4700 . \text { dta, clear } \\
\text { gen year }=\mathbf{2 0 0 6}\end{array}$ \\
\hline $\begin{array}{l}10 \\
(\mathrm{R})\end{array}$ & 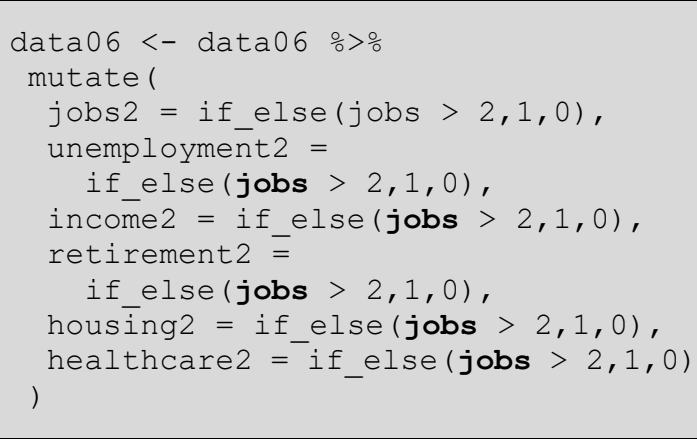 & 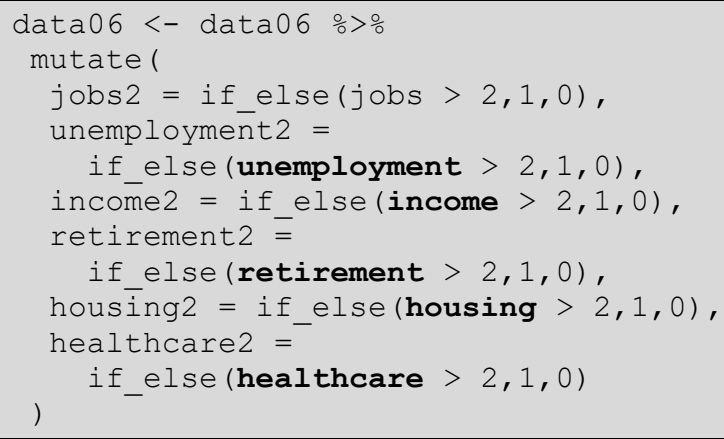 \\
\hline $\begin{array}{c}41 \\
\text { (MPlus) }\end{array}$ & $\begin{array}{l}\text { MODEL: } \\
\text { jobs on foreignpct } \\
\text { Y2006 CND FRA GER IRL } \\
\text { JPN NZL NOR SPA SWE SWZ } \\
\text { GBR USA }\end{array}$ & $\begin{array}{l}\text { We did not curate this code because the team } \\
\text { noted: "they don't mention which country was } \\
\text { used as the reference category (we used } \\
\text { Australia)". Therefore, from the team's } \\
\text { perspective this was not a mistake, even though } \\
\text { original Stata code was available to } \\
\text { demonstrate the U.S. as reference category. }\end{array}$ \\
\hline
\end{tabular}

NOTE: grey highlight indicates actual code snippets from the team's workflow and our curations thereof; bold indicates mistakes and curations.

\section{Procedural (62 in 39 teams)}

Researchers routinely took slightly different coding steps than the original researchers. We see these steps as procedural because we assume this is how the teams always do their research rather than decisions consciously made unique to this particular study. For the OG in particular, these types of error reflect the team's best efforts to reproduce models to which they had no original code and minimal description. We assume they were often left to draw on their own procedural experiences. The typical examples of procedural differences relate to the coding of socio-economic status variables. For example, some teams coded an employment status of "helping a family member" into "not in labor force" when the original study coded this as "part-time work". Others coded this same variable as "unemployed" and some coded "unemployed" as "not in labor force". Two teams disaggregated this variable into "full" and "parttime" based on a third variable measuring hours of work per week. In the TG, these recoding decisions were less common.

The way teams treated missing values was also a common source of variation in both groups. Some used listwise deletion on all variables, some only on all four dependent variables and others did no deletion 
of missing values letting the software instead remove them for each model. A peculiar problem arose in some cases where dummy variables were coded with the object of interest as "1" (like 'in labor force') and then all others (including true missing values) coded as " 0 " meaning that values were added to the analysis that were dropped in the original study.

Other influential steps in the process were decimal place reporting and the software used. After conducting this study, we are painfully aware that R's base programming language rounds the value 0.005 to 0.00 , while Stata rounds it to 0.01 . This alone undermines attempts to find exact replication at two decimal places across software platforms. Moreover, teams themselves reported varying degrees of precision ranging from 1 to 3 decimal places. Other cases include keeping only the Western German sample and dropping those from the Eastern German sample as representative of Germany. This is a common practice for studies that include data prior to 1990 or analyzing data close to 1990, thus it is considered procedural. Also, if a team uses SPSS and point-and-clicked their way through data recoding, we see this as procedural; but it also receives a Missing Component categorization. Examples of this and the following category are in Tables 3 and 4 in the following section.

\section{Mistake-Procedural (22 in 18 teams)}

There are many cases where we cannot safely conclude that it was a mistake or a product of a research team's standard approach to working with data as defined above. This category is dominated by recode variations for the socio-economic variables. The TG technically had all information necessary to recode variables identically to the original study; however, this information was not entirely presented in the manuscript and some could only be exactly replicated via procedural steps (i.e., luck) or with the team doing a forensic analysis of the original study's Stata code. Table 3 lists the most common recodes in this and the Procedural category, and Table 4 gives some concrete examples. These same differences in recoding socio-economic status are coded "Procedural" for the OG and "Mistake-Procedural" for the TG. 
Table 3. Common Procedural Recoding Variations

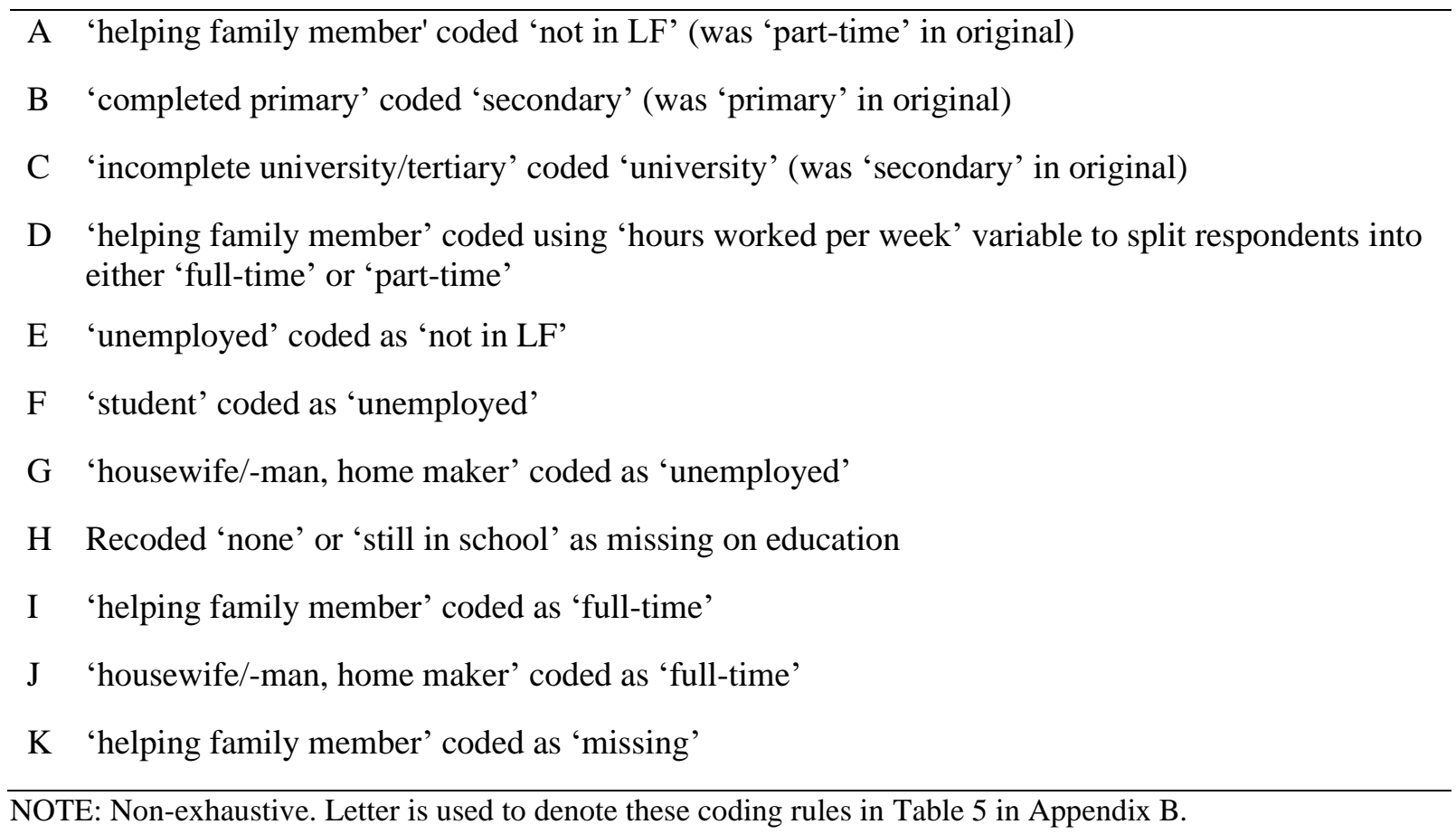

In Table 4, we offer examples. The top row provides the original scoring of the variable v205 from the 1996 wave of ISSP data indicating the educational qualification level. The second row is Stata code from the original study. Below that is a snippet from Team 39 and an example of a Mistake-Procedural category as a source of error from the TG. They did not assign the value of "1" to a code so it was recoded into "." which is Stata's code for missing. It should have been coded "1" for 'less-than-high-school'. This is not safely categorized as Procedural as the team had access to the original code. Then again, if the team focused on the writing in the methods section of the journal article, they would not have known exactly what to do in this recoding step; it is only clear by reading the original code. Thus, in our categorization scheme it is Mistake-Procedural. In the final row is a snippet from Team 83 and an example of a Procedural category from the OG. Their R code recoded those who had incomplete university education as having completed university, but this should have been coded "2" to indicate only secondary education completion (the variable "hs" in the original study). We do not code this as a mistake because the OG did not have access to the original code and had to use their best judgement, because precise definitions of "secondary [education]" were not provided in the Methods Section they were given (see Appendix A). By definition, Mistake-Procedural and Procedural are identical types of error in the code, but take on their different categories based on experimental grouping assignment. 
Table 4. Examples of Procedural Categorizations

\begin{tabular}{|c|c|}
\hline Source & Coding \\
\hline $\begin{array}{c}\text { Original } \\
\text { ISSP } \\
1996 \\
\text { data } \\
\text { codebook } \\
\text { (p. } 118)\end{array}$ & $\begin{array}{l}\text { v205 <DEGREE> R: EDUCATION II: categories } \\
\text { 01. None, still at school } \\
\text { 02. Incomplete primary } \\
\text { 03. Primary completed } \\
\text { 04. Incomplete secondary } \\
\text { 05. Secondary completed } \\
\text { 06. Incompl+compl.semi-higher+incomplete university } \\
\text { 07. University completed }\end{array}$ \\
\hline $\begin{array}{c}\text { Original } \\
\text { study } \\
\text { (Stata) }\end{array}$ & $\begin{array}{l}\text { rename v204 edyears } \\
\text { rename v205 edcat } \\
\text { recode edcat }(1 / 3=1) \quad(4=2)(5=3) \quad(6=4) \quad(7=5), \text { gen (degree) } \\
\text { label define edlabels } 1 \text { "Primary/less" } 2 \text { "Some Secondary" } 3 \text { "Secondary" } 4 \\
\text { "Some Higher Ed" } 5 \text { "University or higher" } \\
\text { label values degree edlabels } \\
\text { recode degree }(1 / 2=1) \text { (nonmiss }=0) \text {, gen(lesshs) } \\
\text { recode degree }(3 / 4=1) \text { (nonmiss }=0) \text {, gen(hs) } \\
\text { recode degree }(5=1) \text { (nonmiss }=0), \text { gen (univ) }\end{array}$ \\
\hline $\begin{array}{l}\text { Team } 39 \\
\text { (Stata) }\end{array}$ & $\begin{array}{l}\text { recode v205 ( } 2 / 4=1 \text { "less than secondary") ( } 5=2 \text { "secondary") (6 } 7=3 \\
\text { "higher than secondary") (else=.), gen (edu) }\end{array}$ \\
\hline $\begin{array}{l}\text { Team } 83 \\
\quad(\mathrm{R})\end{array}$ & $\begin{array}{l}\text { rename (education }=\mathrm{v} 205) \text { \% }>\text { } \\
\text { mutate (education }=\text { recode (education, "Incpl primary" = 1, "Incpl secondary" } \\
\quad=1 \text {, "Primary compl" = 1, "None; still at school, uni" = 1, "Secondary } \\
\text { compl" = 2, "University compl" = 3, "Semi-higher, Incpl uni." = 3)) }\end{array}$ \\
\hline
\end{tabular}

NOTE: bold are specifc sources of error

The Mistake-Procedural category also appeared in the OG in cases where more blatant socioeconomic status miscoding occurred. One example is Team 84 who recoded 'less than part time' as 'unemployed' and also 'other/not in labor force' as missing. Again, this is categorized here because there are plausible arguments behind these decisions. These and others that were larger deviations than those listed in Table 3 were coded as Mistake-Procedural rather than Mistake. In three cases, the teams used some form of robust clustering of standard errors. This was explicitly not mentioned in the provided Methods Section; however, this model feature could be a reasonable assumption when asked to design a model with country and wave dummies (i.e., a basic multilevel model), putting this error into this category. 


\section{Missing Component (4 teams)}

Four teams had missing parts of their workflow rendering it not reproducible. Some users of SPSS did point-and-click recoding and merging of their data, and some teams did data-preprocessing that they simply did not save. For these cases curation is of course not possible, because asking them to redo their analyses would alter the ecological goals of the study.

\section{Interpretational (3 teams)}

In three cases in the OG, the team interpreted the description of the models in a manner different from those reported in the original study. Two involved the centering of independent variables. Although the Methods Section provided to the OG did not mention this step, it also did not specifically offer instructions for any transformations of continuous variables such as age; thus, did not mention not to take this step either. As it is plausible to interpret a multilevel model as involving centering of some or all continuous variables, this type of error is categorized here. The third case involved selecting data based on the Methods Section statement that "all thirteen rich democratic welfare states with data for both waves are included". The team selected on the provided country-level data, which was actually available for 17 countries and they randomly selected 13; whereas our intention was that they select on available individuallevel data for which there are only 13 countries in both waves, but this was not explicit and the team even mentioned this in their workflow notes. As these were issues of interpretation, we did not curate them.

\section{Questionable Method Knowledge (3 teams)}

Our call for researchers explicitly asked for basic regression analysis skills including multilevel modeling. However, three teams demonstrated that they might not possess such skills. In one case, the team admitted to using Stata for the first time, this reflects a lack of software knowledge. In two other cases, the teams analyzed the two separate waves of data in separate regressions, rather than a pooled model with dummy variables for country and wave. Of course, we cannot curate methods competence. It is perhaps bad luck, or a result of the less transparent materials that we have this category, given that both teams who analyzed waves separately were in the OG. However, we suspect that it is most likely a lack of awareness because the Method Section they were given stated, "The ISSP data from 1996 and 2006 are pooled and all thirteen rich democratic welfare states with data for both waves are included [...] These models therefore have dummy variables for countries and years" (see Appendix A).

To summarize this section: The qualitative results demonstrate a wide range of error sources. Without reference to any numeric reproducibility rates they show there is analytic flexibility, or what Gelman and Loken (2014) refer to as researcher degrees of freedom, even in research that should not involve 
any decisions. This surely is the case in the TG where they were provided with the original analytical code. Gary King (1995) refers to provision of original code as the most elegant way to engage in reproducible research, but these results demonstrate that even elegant code does not guarantee elegant reproducibility. What is striking is that much of the errors summarized above are procedural. That is to say not really based on conscious analytical decisions, but occurred as the teams engaged in their research practices drawing on their own defaults and learned software routines. We next combine our qualitative and quantitative findings to better understand the sources of error.

\section{Decomposition of Error}

To shed light on sources of error we run regressions separately for raw and curated results by group (Tables 6 and 7 respectively). In Table 6, the first column presents pooled results. We interpret the linear probability regression coefficients as indicative of a higher statistical likelihood of a Verification (=1) if the team used Stata software (0.14), and if they were 1 point higher on a 5-point statistics skill (-0.03) and perceived difficulty $\left(-0.14^{* *}\right)$ scale. They were less likely if they have a sociology degree $(-0.03)$ in reference to those with political science or other degrees. Teams were much more likely to verify if they were in the transparent group (TG) $\left(0.25^{* * *}\right)$. Perceived difficulty and being in the TG are the clearest predictors of Verification. We use NHST p-values at three cutoffs to help the reader gauge how reliable each effect is; in other words, how unlikely it is to observe our data if the null hypothesis of the coefficient being zero ('no effect') were true. We place no interpretational weight on coefficients that are both small and do not have a low p-value. The adjusted R-square suggests that we can explain about $26 \%$ of the teamlevel variation in results. It is therefore possible that up to $74 \%$ of the variation in results is due to noise rather than observable patterns.

Group-specific results suggest that Stata users were far more likely to verify, exactly replicate and have less error than non-Stata users in the TG. This is logical given that the original study's code was Stata and was only available to the TG. Perceived difficulty also associates with less reproducibility, although the effects are smaller and not always as clearly different from zero. We realize that having such low case numbers does not allow us to take a strong statistical stance. For example, the Stata users in the OG have noticeably less Replication Error when using Stata. The correlation on its own is significantly different from zero in a NHST (0.22), but this disappears in the multivariate regression. Given that R is relatively new in the social sciences, its users may have less experience or were given less didactic support in their methods training compared to Stata, a claim supported by a significant negative correlation of Stata with Difficult in both groups (-0.17 TG, -0.39 OG) (see Table 9, Appendix B for correlations). 
In the OG very little variance is explained. For Verification this is $9.5 \%$ and the adjusted R-square cuts off at zero for both Exact Replication and Replication Error meaning that we cannot statistically explain anything with these variables. This contrasts sharply with the TG. We have two mutually non-exclusive interpretations of this. First, researcher variability is mostly random when replication materials are scant and there is no code. Second, researcher variability gets more random as we increase the precision of our measures. Getting an exact numerical result or minimizing a continuous error measure require much greater accuracy.

Table 6. Multivariate Analysis Predicting Reproducibility Measures, Raw Results, $\mathbf{N}=85$ Teams

\begin{tabular}{llccccccccc}
\hline & \multicolumn{3}{c}{ Verification } & \multicolumn{3}{c}{ Exact Replication } & \multicolumn{3}{c}{ Replication Error } \\
Variable & Pooled & TG & OG & Pooled & TG & OG & Pooled & TG & OG \\
\hline (Intercept) & $0.43^{* * *}$ & $0.59^{* * *}$ & $0.49^{* * *}$ & $0.89^{* * *}$ & $0.91^{* * *}$ & $0.91^{* * *}$ & $0.09^{*}$ & $0.03^{* * *}$ & 0.10 \\
Stata & 0.14 & $0.24^{*}$ & 0.01 & 0.04 & $0.07^{*}$ & -0.01 & -0.03 & $-0.02^{*}$ & -0.04 \\
Stat-skill & -0.03 & $-0.06^{*}$ & 0.00 & -0.01 & -0.02 & -0.00 & -0.01 & $0.00^{*}$ & -0.02 \\
Difficult & $-0.14^{* *}$ & $-0.17^{*}$ & $-0.13^{*}$ & $-0.06^{*}$ & -0.04 & $-0.08^{*}$ & -0.01 & 0.01 & -0.02 \\
Sociology & -0.03 & & & -0.02 & & & 0.01 & & \\
degree & & & & & & & & & & \\
TG & $0.25^{* * *}$ & & & 0.05 & & & -0.06 & & \\
\hline Observations & 85 & 39 & 46 & 85 & 39 & 46 & 85 & 39 & 46 \\
$\mathrm{R}^{2}$ & 0.305 & 0.272 & 0.156 & 0.166 & 0.214 & 0.143 & 0.052 & 0.271 & 0.028 \\
$\mathrm{R}^{2}$ adjusted & 0.261 & 0.209 & 0.095 & 0.114 & 0.147 & 0.081 & 0.000 & 0.209 & 0.000 \\
\hline & & & & & & $* p<0.05 * * p<0.01$ & $* * * p<0.001$
\end{tabular}

NOTE: Verification and Exact Replication are linear probability models and Replication Error are OLS regressions. Degree left out of group-specific regressions due to low predictive power and smaller sample sizes. TG $=$ Transparent group with access to all materials and $\mathrm{OG}=$ opaque group with no code and less methodological information.

Turning to the curated results, most statistical associations remain similar. What is new is that the TG now has very little explained variance. This is not surprising given that our curation removed almost all variance in Verifiability $(98.2 \%=$ " 1 ”). The more striking change is a much higher degree of explained variance in the OG. We attribute this to the curation of major mistakes whenever possible. These results support a conclusion that mistakes are generally random when the original code is not available. Once we remove the random mistakes and the random variation in replication results they cause, we are left with more clearly detectable associations between perceived difficulty of the task and the accuracy of the outcome. If the curated results are more ecologically valid than the raw results then we would conclude that error is a 
product of the researcher's own abilities and challenges encountered in their research, whereas the raw results suggest that error is mostly random if the researchers lack access to the original code.

Table 7. Multivariate Analysis Predicting Reproducibility Measures, Curated Results, $\mathbf{N}=85$ Teams

\begin{tabular}{|c|c|c|c|c|c|c|c|c|c|}
\hline \multirow[b]{2}{*}{ Variable } & \multicolumn{3}{|c|}{ Verification } & \multicolumn{3}{|c|}{ Exact Replication } & \multicolumn{3}{|c|}{$\underline{\text { Replication Error }}$} \\
\hline & Pooled & TG & OG & Pooled & $\mathrm{TG}$ & OG & Pooled & $\mathrm{TG}$ & OG \\
\hline (Intercept) & $0.53^{* * *}$ & $0.75^{* * *}$ & $0.56^{* * *}$ & $0.93^{* * *}$ & $0.98^{* * *}$ & $0.93^{* * *}$ & $0.02^{* *}$ & $0.01^{* *}$ & $0.02^{*}$ \\
\hline Stata & 0.08 & 0.12 & 0.04 & 0.01 & 0.00 & 0.01 & -0.00 & -0.01 & 0.01 \\
\hline Stat-skill & -0.02 & -0.03 & -0.01 & -0.01 & -0.01 & -0.01 & 0.00 & 0.00 & 0.00 \\
\hline Difficult & $-0.13^{* *}$ & -0.10 & $-0.15^{* *}$ & $-0.06^{* * *}$ & -0.00 & $-0.09^{* * *}$ & $0.02^{* * *}$ & 0.00 & $0.03^{* * *}$ \\
\hline $\begin{array}{l}\text { Sociology } \\
\text { degree }\end{array}$ & 0.01 & & & -0.00 & & & -0.00 & & \\
\hline TG & $0.24^{* * *}$ & & & 0.04 & & & $-0.01^{*}$ & & \\
\hline Observations & 85 & 39 & 46 & 85 & 39 & 46 & 85 & 39 & 46 \\
\hline $\mathrm{R}^{2}$ & 0.334 & 0.142 & 0.221 & 0.232 & 0.048 & 0.293 & 0.313 & 0.101 & 0.372 \\
\hline $\mathrm{R}^{2}$ adjusted & 0.292 & 0.069 & 0.165 & 0.183 & 0.000 & 0.242 & 0.269 & 0.024 & 0.327 \\
\hline
\end{tabular}

NOTE: Verification and Exact Replication are linear probability models and Replication Error are OLS regressions. Degree left out of group-specific regressions due to low predictive power and smaller sample sizes. TG $=$ Transparent group with access to all materials and $\mathrm{OG}=$ opaque group with no code and less methodological information.

Finally, we investigate our qualitative categories Mistake and Procedural using regression analyses. To do this we subset our team sample first to include only those teams that had at least one instance of the category Mistake or Mistake-Procedural (=1) compared to all other teams $(=0)$, with those having only Procedural being dropped. Next we do a subset where cases are kept with at least one instance of Procedural and Mistake-Procedural (=1) with those having any Mistake dropped. 
Table 8. Multivariate Analysis Predicting Qualitatively Categorized Sources of Error

\begin{tabular}{lllllll}
\hline \hline & \multicolumn{3}{c}{ Mistake } & \multicolumn{3}{c}{ Procedural } \\
\hline \hline & $\underline{\text { Pooled }}$ & $\underline{\mathrm{TG}}$ & $\underline{\mathrm{OG}}$ & $\underline{\text { Pooled }}$ & $\underline{\mathrm{TG}}$ & $\underline{\mathrm{OG}}$ \\
(Intercept) & $0.67^{* * *}$ & $0.51^{* * *}$ & $0.58^{* * *}$ & $0.63^{* * *}$ & $0.42^{* * *}$ & $0.51^{* *}$ \\
Stata & -0.14 & $-0.30^{*}$ & 0.01 & -0.07 & $-0.29^{*}$ & 0.13 \\
Stat skill & 0.05 & $0.10^{* *}$ & -0.02 & 0.05 & $0.10^{* *}$ & -0.01 \\
Difficult & $0.20^{* *}$ & $0.28^{* *}$ & 0.16 & $0.22^{* *}$ & $0.35^{* * *}$ & 0.21 \\
Exp & $-0.29^{* *}$ & & & $-0.38^{* *}$ & & \\
\hline Observations & 77 & 38 & 39 & 72 & 34 & 38 \\
$\mathrm{R}^{2}$ & 0.240 & 0.366 & 0.102 & 0.291 & 0.543 & 0.086 \\
$\mathrm{R}^{2}$ adjusted & 0.198 & 0.310 & 0.026 & 0.249 & 0.497 & 0.006 \\
\hline \hline
\end{tabular}

NOTE: Linear probability models.

In Table 8, we see that the perceived difficulty of the replication and being in the OG led to much higher instances of Mistake and Procedural errors. Keeping in mind that there is a high correlation of Stata and Difficult, it is unsurprising that the p-values are above our cutoffs when we run group-specific regressions. We provided p-values owing to convention but again do not place a strong stake given sample sizes. The explained variance in the TG is high and driven mostly by whether the team used Stata or not. The explained variance is low in the $\mathrm{OG}$ and is driven by the effect of Difficult. We are left with the impression that both Mistakes and Procedural sources of error are more likely to arise if the researchers face greater subjective difficulty in completing their research tasks, regardless of the transparency of materials. Again, here we refer to the correlation of Stata and Difficult, which suggests that those using Stata are slightly better trained or have more experience than users of $\mathrm{R}$, at least for now. 


\section{Conclusion}

Under the assumption of ecological validity for this crowdsourced study, computational replications are rarely over $95 \%$ reliable. At the inter-researcher level, and given the most transparent conditions, $87.2 \%$ of teams verified the original study, with verification success defined as $95 \%$ of withinteam replicated effects were numerical verifications. At the effect-level this is much higher, but only crosses a 95\% success threshold under two conditions. Either the original study is highly transparent (95.7\% observed verification rate in raw results for the transparent group), or if the researchers are highly motivated and focused so they do not make major mistakes (95.2\% observed pooled curated results). Both the team and effect levels are potentially valid measures of verifiability. In particular, the effect-level could be taken as an observed study-level if we consider that many real-world studies have only one model or effect of interest. Then again, there is increasing attention to robustness and many models meaning that 40-48 models is also a study-level representation of social science. Yet even if we take the effect-level as our preferred metric, a stricter numerical definition of computational reproducibility at the two-decimal place wipes out reliability completely; in all conditions we observed neither effect-level nor team-level rates crossed or even approached $95 \%$. Even if we take the team-level average, we come to a similar conclusion because the pooled average of average within-team verification rate is $91.8 \%$ (see Table 1 in Appendix), and even with curation it remains below $95 \%$.

Using our binomial probability simulation in Figure 1 and using the raw effect-level pooled verification results of this study (92.5\%) it would take at least 3 independent replicators to achieve reliability, when this is defined as a majority of replications coming to the correct result $95 \%$ of the time. We encourage use of the pooled result as our current best approximation because it lies between two extremes of transparency. If we demand $95 \%$ of within-team effects be verifications then it would take more than 10 replications per study because less than $70 \%$ of teams could achieve such three-way reliability - a binomial probability of a majority of replications, $95 \%$ of the time and with $95 \%$ of within-team effects verified.

Unpacking the results, we learn more about the kinds of errors researchers commit. We have no metric to quantify the ecological validity of our study, but based on experiences draws from various behavioral and social science disciplines we know that errors are common in published research. These errors lead to a lack of reproducibility, because they reduce the quality of information and materials available for a potential replicator. This lends some credence to our results, where many mistakes occurred 
and researchers explicitly did things they did not intend, like coding real values of a variable to zero, replacing the values of one variable with another or mixing up identifiers when using multiple waves of a survey.

Many more sources of variability are what we deem to be procedural errors where researchers or their software have varying defaults such as rounding rules, how the data are stored or use of different statistical routines leading to different outcomes. For example, based on training, researchers might take seemingly tiny different steps in dealing with missing codes, like whether they recode a variable constructed out of several other variables to missing or zero. Different researchers have different methodological or disciplinary training and institutional access to software leading to modes of operation that are procedurally rather than intentionally varying across researchers. Consider a scenario where researchers publish a study and their regression models are completely verifiable. The code is shared publicly and replicators should reproduce the exact same results every time. However, replicators might need to download the data from a repository and the data may have changed (new version), something some archives do without version control (Breznau 2016). Even if the data are the same, differences between operating systems, packages and processors can produce different results (McCoach et al. 2018). Default settings often change across versions or software packages. These contexts are a product of what is known and available, thus idiosyncratic to researchers. This type of error is not readily observable, or easily categorized as a mistake or a choice. For example, does lack of access to Stata constitute a choice or a mistake? We would argue it is neither.

In our multivariate analyses we see that less transparent materials increased the inter-researcher error rates substantially. Otherwise, the perceived difficulty of a task for both experimental groups and the use of a different software than the original as it was provided for the transparent group were also important predictors of error. When predicting the two largest categories making mistakes and committing procedural types of error, we again see perceived task difficulty as an important predictor; however, reading the explained variance in our regressions suggests that a majority of errors may be random, or at least deriving from unknown sources. Here we suggest that these sources come from idiosyncratic features of the researchers and their research processes. It is something unconscious, or preconscious, to the process of research and the researcher, something hard to observe and not part of the modeling process or research design. It depends largely on tacit knowledge that researchers require to execute their studies that "cannot be fully explicated or absolutely established" in practice (Collins 1985:73). 


\section{DisCUSSION}

We assume that these results generalize beyond computational reproduction to more complex tasks where researchers must make many decisions. In such cases we expect inter-researcher reliability to drop even more. Lacking transparent materials leads to computational reproductions that are more like standard research because researchers are forced to make several decisions owing to a lack of information. Here our study links to analogous evidence suggesting inter-researcher variability when researchers conduct similar original research tasks as seen in many analyst studies (Bastiaansen et al. 2020; Breznau 2016; Dutilh et al. 2019; Landy et al. 2020; Silberzahn et al. 2018). Unfortunately, the generalizability of these findings beyond simple computational verification is difficult to test, given the challenge in obtaining a reliable prior probability of coming to certain results in any given study. We do not know if an original study is 'correct', and mistake-free. Prediction markets or z-curves are suggested options to estimate plausible expected replicability rates (Dreber et al. 2015; Schimmack 2020), but any attempt to identify a 'true' replicability rate can quickly digress into a philosophical mire regarding the nature of truth.

We still argue that our observations suggest that subtleties and idiosyncrasies creep into the process of research leading to outcome variation. If this is true in any kind of research involving data analysis, then the question changes from 'how many replicators...' to 'how many researchers are necessary to achieve reliability?'. Real-world phenomena are already hidden from observation by various layers of measurement error and under-developed theory and models (Auspurg and Brüderl 2021). Researcher variability adds an additional meta-source of error that is not explicitly measurement or model misspecification related in the sense that it does not derive from the act of conscious measurement or modeling decisions. Thus, uncertainty is likely higher than we calculate in a single study, because other researchers performing the same study would not get the same results every time.

In addition to lacking the tools to easily observe and quantify inter-researcher variability except in the unique case of computational reproduction, our study is not without limitations. It is possible that the peculiarities of this task involving ISSP data with a 10-category employment variable and a 7-category education variable (at least in the 1996 wave) made researchers particularly prone to procedural variability. Our only counter to such an assertion would be that sociologists do a great deal of survey-based research and most surveys generate data on ISCO codes, education categories (that often vary by country) and several labor market statuses that are not always consistent (like respondents reporting being "unemployed" in one question and working "part-time" in another). Therefore, sociologists with survey data analysis experience should be quite comfortable with the tasks in this study. This is true across many social science disciplines, a finding supported indirectly by a lack of correlation of sociology degree with committing procedural types of error. 
We are also limited in our ability to draw a population inference from our sample. We have close to $95 \%$ replication of effects, but when we reduce this to the team-level, only 87.2 and $64.1 \%$ of teams could unanimously verify and exactly replicate the original study respectively. This seems like the appropriate unit of analysis as each is an independent replication. But we cannot know how much sampling variation might have caused this as there is no straightforward way to define the global sample of potential replicators. This could include anyone who has working knowledge of multilevel modelling and working with survey and country-indicator data, or be limited to those with experience in the topical area. Followup studies should consider limiting participation to only experts on the topic, a particular discipline, or some other criteria designed to eliminate additional noise likely generated in our effort to measure interresearcher reliability.

Our conclusions, like our study also have limitations. 'How many replicators?' may not be the right question. Replications will not necessarily cure inter-researcher variability. First, three replications or more per study is, at least in the current state of social science, an absurd expectation to uphold. Replications are already quite rare. In our current conjuncture, we are lucky to see one replication of any given study (Breznau 2021). Second, journals tend to avoid replications, especially ones that overturn their own previously published results, and replications are time-consuming and often not institutionally supported. If researcher variability leads to a meta-source of error large enough to be a causal factor in the current reliability crisis, replications will help very little.

Our study highlights the need for maximal transparency about the research process. We have ethical codes calling for transparency, and journal 'policies' that follow suit. But there is no enforcement and sociologists regularly do not share their materials (Freese 2007; Young 2015; Zenk-Möltgen et al. 2018). In our study, the opaque group attempted to replicate under very in-transparent conditions, without code and without even numerical results. Not surprisingly this experimental group was far less likely to verify the original study. This is an extreme case and we do not expect studies to be published without their numerical results; however, we expect code sharing and clearly demonstrated that without code, replication error rates increase markedly. This could be damaging to the scientific process because it could lead to false doubt on the validity of social science research where it is unwarranted, and thus generate additional work for both replicators and especially original study authors who then rush to defend their falsely aspersed studies. To be clear, transparency is a low cost alternative to larger-scale methods of "stabilizing" estimate uncertainty like the crowdsourced replication we conducted or even larger Metaketa efforts (Dunning et al. 2019). A sociologist should not need ethical rules or enforcement mechanisms to generate and share high quality code when informed about these cost-benefits; that is if their goal is efficient and reliable collective knowledge. 
Regarding the original study of Brady and Finnigan (2014) we offer no recourse. They found results in all directions and concluded that there was no general effect of immigration on policy preferences, thus it would take an extremely unlikely wave of positive or negative coefficients to overturn this. This is not something that noise from researcher variability is likely to cause. If the crowdsourced replication were repeated, it might be more interesting to target a study with overwhelmingly positive or null test results, to see if their robustness holds given the introduction of meta-noise. All we can conclude from the crowdsourced replication is that the impact of researcher variability is to make any single replication effect potentially unreliable.

In conclusion, we underscore that researchers, through very little effort, can substantively come to different results. This means that if a researcher has a motivation to find support or rejection of a hypothesis, even under controlled conditions where there should not be any research choices, they can theoretically find that support. This is one in a frenzy of warnings coming out of science in recent years about the reliability of research. Simultaneously we must humbly concede that some variability is beyond our control. Merton argued that sociological credibility depends on researchers arriving at similar answers (Merton 1973), but the results of this study suggest that there are limits to credibility that might simply exist in the process of research. Even the most 'elegant' form of transparency via code sharing (King 1995) does not guarantee that researchers can fully reproduce previous results or perfectly interpret the models used. But it would certainly help a great deal. 


\section{REFERENCES}

Auspurg, Katrin, and Josef Brïderl. 2021. "Has the Credibility of the Social Sciences Been Credibly Destroyed? Reanalyzing the 'Many Analysts, One Data Set' Project by Causal Reasoning and Multiverse Analysis."

Bastiaansen, Jojanneke A., et al. 2020. "Time to Get Personal? The Impact of Researchers Choices on the Selection of Treatment Targets Using the Experience Sampling Methodology." Journal of Psychosomatic Research 137:110211. doi: 10.1016/j.jpsychores.2020.110211.

Botvinik-Nezer, Rotem, et al. 2020. "Variability in the Analysis of a Single Neuroimaging Dataset by Many Teams.” Nature 582(7810):84-88. doi: 10.1038/s41586-020-2314-9.

Breznau, Nate. 2016. "Secondary Observer Effects: Idiosyncratic Errors in Small-N Secondary Data Analysis." International Journal of Social Research Methodology 19(3):301-18. doi: 10.1080/13645579.2014.1001221.

Breznau, Nate. 2021. "Does Sociology Need Open Science?" Societies 11(1):9. doi: $10.3390 /$ soc11010009.

Breznau, Nate, Eike Mark Rinke, and Alexander Wuttke. 2018. "Pre-Registered Report for 'How Reliable Are Replications? Measuring Routine Researcher Variability in MacroComparative Secondary Data Analyses." SocArXiv. https://osf.io/sfuq3/

Breznau, Nate, Eike Mark Rinke, and Alexander Wuttke. 2019. "Crowdsourced Replication Initiative: Executive Report.”SocArXiv. https://osf.io/preprints/socarxiv/6j9qb/

Breznau, Nate, et al. 2021. "Observing Many Researchers Using the Same Data and Hypothesis Reveals a Hidden Universe of Data Analysis."

Collins, Harry M. 1985. Changing Order: Replication and Induction in Scientific Practice. London, Beverly Hills \& New Delhi: Sage Publications.

Dreber, Anna, Thomas Pfeiffer, Johan Almenberg, Siri Isaksson, Brad Wilson, Yiling Chen, Brian A. Nosek, and Magnus Johannesson. 2015. "Using Prediction Markets to Estimate the Reproducibility of Scientific Research." Proceedings of the National Academy of Sciences 112(50):15343-47. doi: 10.1073/pnas.1516179112.

Dunning, Thad, Guy Grossman, Macartan Humphreys, Susan D. Hyde, Craig McIntosh, and Gareth Nellis, eds. 2019. Information, Accountability, and Cumulative Learning: Lessons from Metaketa I. 1st ed. Cambridge University Press.

Dutilh, Gilles, et al. 2019. "The Quality of Response Time Data Inference: A Blinded, Collaborative Assessment of the Validity of Cognitive Models.” Psychonomic Bulletin \& Review 26(4):1051-69. doi: 10.3758/s13423-017-1417-2. 
Eubank, Nicholas. 2016. "Lessons from a Decade of Replications at the Quarterly Journal of Political Science." PS: Political Science \& Politics 49(2):273-76. doi: DOI: 10.1017/S1049096516000196.

Freese, Jeremy. 2007. "Replication Standards for Quantitative Social Science: Why Not Sociology?" Sociological Methods \& Research 36(2):153-72. doi: 10.1177/0049124107306659.

Freese, Jeremy, and David Peterson. 2017. "Replication in Social Science." Annual Review of Sociology 43(1):147-65. doi: 10.1146/annurev-soc-060116-053450.

Gelman, Andrew, and Eric Loken. 2014. "The Statistical Crisis in Science." American Scientist 102(6):460. doi: 10.1511/2014.111.460.

Hardwicke, Tom E., et al. "Data Availability, Reusability, and Analytic Reproducibility: Evaluating the Impact of a Mandatory Open Data Policy at the Journal Cognition." MetaArcXiv Preprints Open Science Framework. doi: 10.31222/osf.io/39cfb.

Head, Megan L., Luke Holman, Rob Lanfear, Andrew T. Kahn, and Michael D. Jennions. 2015. "The Extent and Consequences of P-Hacking in Science." PLoS Biology 13(3). doi: 10.1371/journal.pbio.1002106.

Herndon, Thomas, Michael Ash, and Robert Pollin. 2013. "Does High Public Debt Consistently Stifle Economic Growth? A Critique of Reinhart and Rogoff." Cambridge Journal of Economics 38(2):257-79. doi: 10.1093/cje/bet075.

ISSP Research Group (1999). International Social Survey Programme: Role of Government III ISSP 1996. GESIS Data Archive, Cologne. ZA2900 Data file Version 1.0.0, doi: 10.4232/1.2900.

Jacoby, William G., Sophia Lafferty-Hess, and Thu-Mai Christian. 2017. "Should Journals Be Responsible for Reproducibility? | Inside Higher Ed.” Inside Higher Ed Blog. Retrieved July 22, 2019 (https://www.insidehighered.com/blogs/rethinking-research/shouldjournals-be-responsible-reproducibility).

Janz, Nicole. 2015. "Leading Journal Verifies Articles before Publication - So Far, All Replications Failed." Political Science Replication Blog. Retrieved July 22, 2019 (https://politicalsciencereplication.wordpress.com/2015/05/04/leading-journal-verifiesarticles-before-publication-so-far-all-replications-failed/).

Jasso, Guillermina. 1986. "Is It Outlier Deletion or Is It Sample Truncation? Notes on Science and Sexuality." American Sociological Review 51(5):738. doi: 10.2307/2095497.

King, Gary. 1995. "Replication, Replication.” PS: Political Science \& Politics 28(3):444-52. doi: $10.2307 / 420301$.

Landy, Justin F., Miaolei Liam Jia, Isabel L. Ding, Domenico Viganola, Warren Tierney, Anna Dreber, Magnus Johannesson, Thomas Pfeiffer, Charles R. Ebersole, and Quentin F. 
Gronau. 2020. "Crowdsourcing Hypothesis Tests: Making Transparent How Design Choices Shape Research Results." Psychological Bulletin.

McCoach, D. Betsy, Graham G. Rifenbark, Sarah D. Newton, Xiaoran Li, Janice Kooken, Dani Yomtov, Anthony J. Gambino, and Aarti Bellara. 2018. "Does the Package Matter? A Comparison of Five Common Multilevel Modeling Software Packages:" Journal of Educational and Behavioral Statistics 43(5):594-627. doi: 10.3102/1076998618776348.

Merton, Robert K. 1973. The Sociology of Science: Theoretical and Empirical Investigations. University of Chicago press.

Nosek, Brian A., Jeffrey R. Spies, and Matt Motyl. 2012. "Scientific Utopia: II. Restructuring Incentives and Practices to Promote Truth Over Publishability." Perspectives on Psychological Science 7(6):615-31. doi: 10.1177/1745691612459058.

Pickett, Justin T. 2020. "The Stewart Retractions: A Quantitative and Qualitative Analysis.” Econ Journal Watch 17(1):152.

Schimmack, Ulrich. 2020. "A Meta-Psychological Perspective on the Decade of Replication Failures in Social Psychology." Canadian Psychology/Psychologie Canadienne No Pagination Specified-No Pagination Specified. doi: 10.1037/cap0000246.

Schweinsberg, Martin, et al. 2021. "Same Data, Different Conclusions: Radical Dispersion in Empirical Results When Independent Analysts Operationalize and Test the Same Hypothesis." Organizational Behavior and Human Decision Processes.

Silberzahn, Raphael, et al. 2018. "Many Analysts, One Data Set: Making Transparent How Variations in Analytic Choices Affect Results." Advances in Methods and Practices in Psychological Science 1(3):337-56. doi: 10.1177/2515245917747646.

Stockemer, Daniel, Sebastian Koehler, and Tobias Lentz. 2018. "Data Access, Transparency, and Replication: New Insights from the Political Behavior Literature." PS: Political Science \& Politics 51(4):799-803. doi: DOI: 10.1017/S1049096518000926.

Wicherts, Jelte M., Coosje L. S. Veldkamp, Hilde E. M. Augusteijn, Marjan Bakker, Robbie C. M. van Aert, and Marcel A. L. M. van Assen. 2016. "Degrees of Freedom in Planning, Running, Analyzing, and Reporting Psychological Studies: A Checklist to Avoid pHacking." Frontiers in Psychology 7:1832. doi: 10.3389/fpsyg.2016.01832.

Young, Cristobal. 2015. "Sociologists Need to Be Better at Replication." Orgtheory. Retrieved (https://orgtheory.wordpress.com/2015/08/11/sociologists-need-to-be-better-atreplication-a-guest-post-by-cristobal-young/).

Young, Cristobal. 2018. "Model Uncertainty and the Crisis in Science." Socius 4:1-7. doi: $10.1177 / 2378023117737206$.

Zenk-Möltgen, Wolfgang, Esra Akdeniz, Alexia Katsanidou, Verena Naßhoven, and Ebru Balaban. 2018. "Factors Influencing the Data Sharing Behavior of Researchers in 
Sociology and Political Science." Journal of Documentation 74(5):1053-73. doi: 10.1108/JD-09-2017-0126. 


\section{Appendix A, Participant Instructions}

\subsection{Transparent Group (TG) Instructions}

In this project we are crowdsourcing the replication of a 2014 study by Brady and Finnigan (B\&F). The published paper and online supplemental materials are attached to this email and in a shared folder (see link below). There are many different types of replication. Your team has only one goal in this first stage of replication. That is to replicate this study to determine verifiability. You are to assess whether the reported results of the study follow appropriately from the data and methods employed by the original authors.

We provide you with the same two waves of International Social Survey Program (ISSP) data, the country-level data, and the analytical code (Stata format) used by B\&F, and you should follow their reported methods as closely as possible to determine if:

1. their results are reproducible - to check their results;

2. the results you find (whether identical or not) confirm their reported conclusions; and

3. the methods they describe in their paper are accurately reflected in their models and results - to check their work.

We ask that you replicate their work using your preferred statistical software. That is the software that your team plans to work in throughout this entire project. This is important because there are many more stages that will build on the code you develop in this stage, and we do not expect you to learn new code for this project. We ask you to assess verifiability of their methods and results, and to do this independently of their Stata code (.do file), although you are welcome to use it as a guide or run it to cross-check your own code. Please do everything that the authors reported doing in executing their analyses. However, it is not necessary to run their supplemental models or analyses for now. At a minimum we ask that you replicate the results from Tables 4 and 5 . If you like you can replicate other models, but we need your verifiability test for Tables 4 and 5 - otherwise the replication will be incomplete.

To ensure that you use the correct version of the ISSP data, download these datafiles from our shared data folder (they are too large to attach to an email), they are in either Stata, .csv, or .xls format and titled ZA2900 and ZA4700. Note that in .csv and .xls format the data contain no meta-data (i.e., no variable labels or differentiation between string and numeric) so you might need access to additional documentation. If you cannot manage to import or work with one of these formats please contact us for transferring the data into your preferred format.

[redacted] (click to access ISSP data, plus other materials left here for convenience; if you do not have HTML enabled email you may copy and paste the link at the end of this email into your browser).

Please be sure that you document all your work and that we can reproduce your results using the code you give us. Please document any cases in which you conclude that the authors' research is not verifiable in either results or the match between what they claim to do and what they actually do (i.e., points 1-3 above). Please write a short summary of your arguments supporting claims that their reported methods do not match their actual methods. If during this replication concerns or ideas arise for different or better analytical strategies than those employed by the original authors, this is great, but please keep them in mind for the phase after the replication when you will be asked to expand 
or improve upon this particular study. But for now, we ask that you do not yet run additional analyses or alternative model specifications as these might bias your task.

Results should be submitted by September 10th, 2018 to [redacted] and must include your code saved in its own language file (e.g., .do, .R, inp, etc) and a results table in spreadsheet format. We provide an attached Excel [template link redacted] where you can fill in your results for B\&F's Tables 4 and 5 , but feel free to replicate their other main models if you are interested. It is not necessary to reproduce or verify their graphs for now.

We know how much time pressure you may face as a productive scholar, but we must stress the importance of completing the replication on time as the success of the project depends on starting the next phase of the CRI on time. We estimate that this exercise may take between 5 and 14 hours of working time depending very much on your own experience with the data and/or the models employed herein. Thank you for your understanding and participation in this exciting initiative. We remind you that all participants completing the CRI tasks will be co-authors on the final paper where we present the results of the study. Do not hesitate to ask if you have questions or need assistance.

\subsection{Opaque Group (OG) Instructions}

You are now asked to replicate a study to start this project. You are assigned to replicate a published study but to do so without knowing the study. We realize this may seem unusual; however, your participation is crucially important to developing deeper knowledge about replication and crowdsourcing. We kindly ask that you attempt to replicate this study to the best of your ability using only the materials we provide, and without spending time trying to 'figure out' where it came from. Again, your cooperation in this collaborative and co-authored research project is of great importance.

Attached to this email is a Methods and Results section from this study, re-written by us to render it anonymous. We ask that you focus entirely on replication and assess the verifiability of the study by:

1. replicating their exact models - to the best of your ability

2. checking if your results match the results described in the Results section

The original authors used two waves of International Social Survey Program (ISSP) data and a few country-level measures. We link you to these data directly in a shared data folder (they are too large to attach to an email), they are in either Stata, .cSv, or .xls format and titled ZA2900 (ISSP 1996), ZA4700 (ISSP 2006), and L2data (for the countrylevel data). Note that in .csv and .xls format the data contain no meta-data (i.e., no variable labels or differentiation between string and numeric) so you might need access to additional documentation. Please work only with the data provided as it is essential to our project that all replication teams work with identical data. If you cannot manage to import or work with one of these formats please contact us for transfering the data into your preferred format.

[redacted] (click to access ISSP and country-level data, if you do not have HTML enabled email please copy and paste the link at the end of this email into your browser).

Please work in the statistical software you normally work with. We ask that you do not learn a new software in order to participate in this initiative. Please be sure that you document all your work and that we can reproduce your results using the code you give us. If you need a additional documentation (e.g., codebooks) there are two links at the end of this email, one for each ISSP wave. If during this replication concerns or ideas arise for different or better analytical 
strategies than employed by the original authors, please keep them in mind for the phase after the replication when you will have the chance to share them and to do them. But for now we ask that you do not yet run additional analyses or alternative model specifications as these might bias your task.

Results should be submitted by September 10th, 2018 to [redacted]. Please include your code saved in its own language file (e.g., .do, .R, .inp, etc) and a results table in spreadsheet format (.csv, .xlsx, .gsheet etc). We provide an attached Excel [template link redacted] to give you an example of the ideal 'style' of results, and if you like you can fill in your results.

We know how much time pressure you may face as a productive scholar, but we must stress the importance of completing the replication on time as the success of the project depends on starting the next phase of the CRI on time. We estimate that this exercise may take between 5 and 14 hours of working time depending very much on your own experience with the data and/or the models employed herein. Thank you for your understanding and participation in this exciting initiative. We remind you that all participants completing the CRI tasks will be co-authors on the final paper where we present the results of the study. Do not hesitate to ask if you have questions or need assistance.

\subsection{Opaque Group (OG) Methods Section}

\section{Dear CRI Participant,}

The following 'Methods Section' is taken from a published study this is re-written in a way that maintains identical methods, but anonymizes it from the original study. We will reveal the original study after you submit your replication results. Please note that the original paper theoretically argued and cited reasons for research choices and conducted several sensitivity analyses with country-level variables that we have purposefully omitted here. We want you to focus on reproducing the procedure described and verifying their conclusions in your replication. If you feel ideally that you require more information to create these models, please just use your best judgement or whatever your standard decision might with the given information. In other words, treat what is below and in the data as the 'universe' of information available to you to reconstruct this study and then do your best. Thank you again for your participation.

Your goal is to produce two tables representing the impact of Immigrant Stock and Change in Immigrant Stock on policy attitudes - reported survey responses regarding the ideal role of government in various social policies. We ask that participants use a style following our preformatted template attached to the email [redacted] for reporting results of the various models and then save in any spreadsheet format (.xls, .csv, etc) that we can easily copy and paste (for example, no .pdf files please). Please include the significance starts in addition to the z-statistics, even though both indicate the p-value, we want you to follow what is 'standard practice' in the literature and draw your conclusions from this. After producing the tables, please compare your results to the descriptive results found in the Results section below. Please indicate if you support the descriptive results in a short written summary and please share your code, including the software and version, and any other tools you incorporated in the replication of this study.

Again, all materials and data are available in the [shared data folder link redacted].

\section{Methods}


$<$ In the following measured variables are italicized and capitalized throughout. $>$

Four policy attitudes are analyzed as dependent variables, taken from the International Social Survey Program (ISSP). These questions start with (in verbatim English), "On the whole, do you think it should or should not be the government's responsibility to ... ." Then there is a module of questions from which we draw variables in the social welfare related domains of, "... provide a decent standard of living for the old" we label this Old Age Care, "... provide a decent standard of living for the unemployed" labeled Unemployed, "... reduce income differences between the rich and the poor" labeled Reduce Income Differences, and "... provide a job for everyone who wants one" labeled Jobs. Respondents chose among ordinal categories of definitely should be, probably should be, probably should not be, and definitely should not be for each. These are collapsed into a dichotomous variable where affirmative answers $=1$.

The main test variables are two country-level indicators of immigration as an absolute and a relative measure. The absolute measure is Immigrant Stock measured as percent foreign-born out of the total population, and the relative measures is Change in Immigrant Stock measured as the net migration number of in-migrants minus the number of out-migrants in the last year taken as a percentage of the total population. Both variables are lagged one year behind the dependent variable. Country-level variables that might otherwise influence social welfare policy attitudes are also included as Social Welfare Expenditures (the commonly used 'SOCX' variables) as a percentage of GDP and Employment Rate (\% of active LF).

A range of individual-level variables expected to uniquely influence social welfare policy attitudes are included. These are Female ( $=1$, male $=0)$, Age and Age-squared, education categories (Primary or less, Secondary and University or more; with secondary as reference), and employment categories (Part-time, Not active, Active unemployed, and Full-time; with full- time as the reference category).

The ISSP data from 1996 and 2006 are pooled and all thirteen rich democratic welfare states with data for both waves are included. Models employing country and year fixed-effects to account for both the nested structure of individuals in countries and to allow for differences between time points are employed. These models are known as "two-way fixed-effects" models in the econometric literature. These models therefore have dummy variables for countries and years.

Given uncertainties in the relationships between country-level variables, different configurations are tested but all having the same individual-level variables. The main results are reported as odds-ratios and z-statistics. Models are numbered for convenience. Models 1-4 include only Immigrant Stock, 5-8 include Immigrant Stock and Social Welfare Expenditures, 9-12 include Immigrant Stock and Employment Rate, 13-16 include only Change in Immigrant Stock, 17-20 include Change in Immigrant Stock and Social Welfare Expenditures, and 21-24 include Change in Immigrant Stock and Employment Rate.

\section{Results}

In the first models (1-4) analyzing the impact of Immigrant Stock, odd-ratios and significance tests suggest that a one percent increase in Immigrant Stock statistically increases the likelihood of agreeing with Old Age Care - an increase significantly different from zero. It has no effect on Unemployment, so an impact not statistically different 
from zero. It statistically decreases the likelihood of agreeing with the variables Reduce Income Differences and Jobs. In the next four models including Social Welfare Expenditures (5-8), Immigrant Stock shows the exact same pattern of direction and significance across the four dependent variables. In the final four models using Immigrant Stock with Employment Rate added in (9-12) results remain the same except that Old Age Care drops out of significance.

Results for Change in Immigrant Stock alone (models 13-16) reveal that it has a statistically significant impact on increasing the likelihood of agreement with Old Age Care and Jobs, while having a not significantly different from zero impact on Unemployment and Reduce Income Differences. Models including Social Welfare Expenditure (1720) do not change these results at all. However, addition of Employment Rate (21-24) leads to Change in Immigrant Stock significantly increasing the likelihood of agreement with all four dependent variables.

This study concludes that there is no systematic impact of immigration on responses to these survey questions, and this is evidence that immigration does not decrease support for the social welfare state. 


\section{Appendix B, AdDitional Tables and Figures}

Table 1. Descriptive Statistics

\begin{tabular}{|c|c|c|c|c|c|c|c|}
\hline \multirow{2}{*}{ Variables } & \multirow[b]{2}{*}{ Measurement } & \multicolumn{3}{|c|}{ Team-Level } & \multicolumn{3}{|c|}{ Effect-Level } \\
\hline & & TG & $\mathrm{OG}$ & Pooled & TG & $\mathrm{OG}$ & Pooled \\
\hline Cases & & 39 & 46 & 85 & 1,872 & 1,874 & 3,746 \\
\hline \multicolumn{8}{|l|}{ Raw Replication Results } \\
\hline Verification & same direction $=1$ & 0.957 & 0.887 & 0.918 & 0.957 & 0.893 & 0.925 \\
\hline Exact Verification & identical at two decimals $=1$ & 0.769 & 0.473 & 0.606 & 0.769 & 0.481 & 0.625 \\
\hline Deviance & $\begin{array}{l}\text { absolute difference with } \\
\text { original }\end{array}$ & 0.013 & 0.073 & 0.046 & 0.013 & 0.071 & 0.042 \\
\hline Deviance, SD & team-level SD & 0.024 & 0.195 & 0.148 & 0.037 & 0.202 & 0.148 \\
\hline \multicolumn{8}{|c|}{ Curated Replication Results } \\
\hline Verification & same direction $=1$ & 0.982 & 0.917 & 0.946 & 0.982 & 0.923 & 0.952 \\
\hline Exact Verification & identical at two decimals $=1$ & 0.839 & 0.556 & 0.683 & 0.839 & 0.566 & 0.702 \\
\hline Deviance & $\begin{array}{l}\text { absolute difference with } \\
\text { original }\end{array}$ & 0.008 & 0.028 & 0.019 & 0.008 & 0.025 & 0.016 \\
\hline Deviance, SD & team-level SD & 0.016 & 0.041 & 0.033 & 0.026 & 0.053 & 0.042 \\
\hline \multicolumn{8}{|l|}{ Independent Variables } \\
\hline Stata & other software $=0$ & 0.67 & 0.63 & 0.65 & & & \\
\hline Sociology Degree & other degrees $=0$ & 0.49 & 0.50 & 0.49 & & & \\
\hline Stats-Skill & 4-question scale & -0.04 & 0.13 & 0.05 & & & \\
\hline SD & & 1.79 & 1.54 & 1.65 & & & \\
\hline Difficulty & 1-question (5 ordinal levels) & 2.10 & 2.24 & 2.18 & & & \\
\hline SD & & 0.79 & 0.77 & 0.77 & & & \\
\hline Team Size & 1-3 persons & -0.09 & 0.02 & -0.03 & & & \\
\hline SD & & 0.64 & 0.86 & 0.77 & & & \\
\hline \multicolumn{8}{|l|}{ Qualitative Categories } \\
\hline Mistake & see text & 0.23 & 0.31 & 0.28 & & & \\
\hline Procedural & see text & 0.15 & 0.71 & 0.47 & & & \\
\hline Mistake-Procedural & see text & 0.21 & 0.21 & 0.21 & & & \\
\hline Missing Component & see text & 0.03 & 0.06 & 0.05 & & & \\
\hline Interpretational & see text & 0.00 & 0.06 & 0.04 & & & \\
\hline $\begin{array}{l}\text { Questionable } \\
\text { Methods Competencies }\end{array}$ & see text & 0.00 & 0.06 & 0.04 & & & \\
\hline
\end{tabular}

NOTE: Standard deviations (SD) for dichotomous variables omitted to save space. Effects are reported odds ratios with regression coefficient p-values as significance scores. Verification are same sign (including 'same' when both are not significantly different from zero, NHST, $\mathrm{p}<0.05$ ), Exact Replication are identical odd-ratios at $<0.01$ and Replication Error is absolute value of the difference between estimated odds ratio and original odds ratio. T-tests comparing the two randomized groups on the variables in the shaded box under Independent Variables reveal that there is no significant mean difference (all p-values were above 0.35 ). Note that team-level values here are simply the means. This differs from Figure 1 where team-level verification and exact replication are defined as $=1$ only if $95 \%$ of within-team effects are replicated. 
Table 5. Qualitative Categorization of Inter-Researcher Error

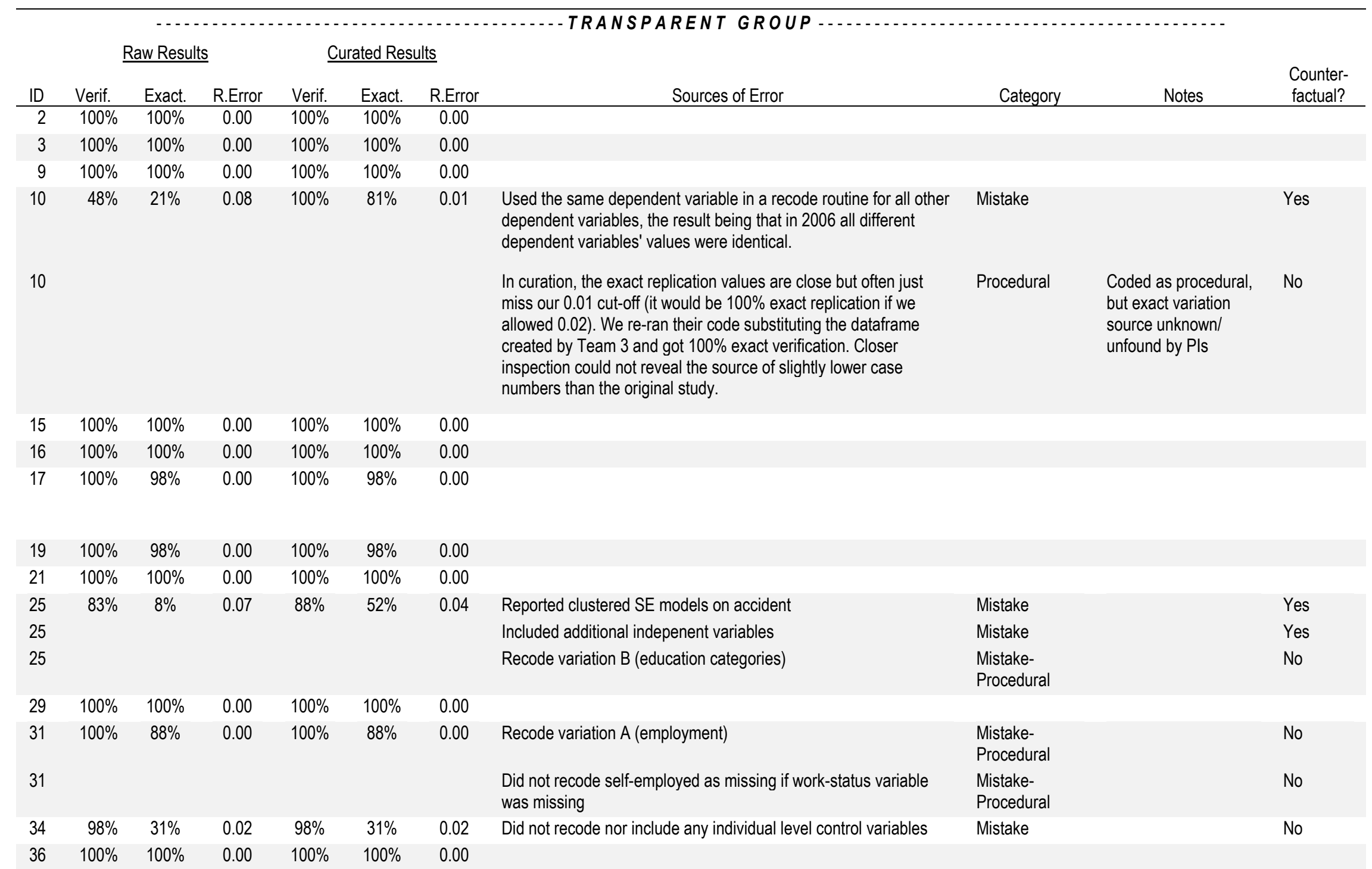

NOTE: Recode variations listed in Table 3, see main text. 
Table 5 Continued. Qualitative Categorization of Inter-Researcher Error

\begin{tabular}{|c|c|c|c|c|c|c|c|c|c|c|}
\hline \multirow[b]{2}{*}{ ID } & \multicolumn{3}{|c|}{$\underline{\text { Raw Results }}$} & \multicolumn{3}{|c|}{$\underline{\text { Curated Results }}$} & \multirow[b]{2}{*}{ Sources of Error } & \multirow[b]{2}{*}{ Category } & \multirow[b]{2}{*}{ Notes } & \multirow[b]{2}{*}{$\begin{array}{l}\text { Counter- } \\
\text { factual? }\end{array}$} \\
\hline & Verif. & Exact. & R.Error & Verif. & Exact. & R.Error & & & & \\
\hline 37 & $100 \%$ & $40 \%$ & 0.01 & $100 \%$ & $40 \%$ & 0.01 & $\begin{array}{l}\text { Recoded missing on income to zero, elected not to counterfactual } \\
\text { as this is a plausible (although highly controversial) procedural } \\
\text { step }\end{array}$ & Procedural & & No \\
\hline 37 & & & & & & & $\begin{array}{l}\text { Coded "Germany" as respondents in former Western Germany } \\
\text { only }\end{array}$ & $\begin{array}{l}\text { Mistake- } \\
\text { Procedural }\end{array}$ & & No \\
\hline 37 & & & & & & & Included N.Ireland as part of "United Kingdom" & Procedural & & No \\
\hline 37 & & & & & & & Recode variation C (education) & $\begin{array}{l}\text { Mistake- } \\
\text { Procedural }\end{array}$ & & No \\
\hline 37 & & & & & & & Recode variation I \& J (employment) & Procedural & & No \\
\hline 38 & $100 \%$ & $100 \%$ & 0.00 & $100 \%$ & $100 \%$ & 0.00 & & & & \\
\hline 39 & $100 \%$ & $79 \%$ & 0.01 & $100 \%$ & $79 \%$ & 0.01 & Recode variation $\mathrm{H}$ (education) & $\begin{array}{l}\text { Mistake- } \\
\text { Procedural }\end{array}$ & & No \\
\hline 39 & & & & & & & Recode variation K (employment) & $\begin{array}{l}\text { Mistake- } \\
\text { Procedural }\end{array}$ & & No \\
\hline 40 & $100 \%$ & $100 \%$ & 0.00 & $100 \%$ & $100 \%$ & 0.00 & & & & \\
\hline 41 & $90 \%$ & $19 \%$ & 0.08 & $90 \%$ & $19 \%$ & 0.08 & Used maximum likelihood estimation & Procedural & $\begin{array}{l}\text { Missing parts of } \\
\text { workflow }\end{array}$ & No \\
\hline 41 & & & & & & & Recoded education as 'none', 'primary' and 'secondary' & Mistake & & No \\
\hline 41 & & & & & & & Recode variation A (employment) & $\begin{array}{l}\text { Mistake- } \\
\text { Procedural }\end{array}$ & & No \\
\hline 41 & & & & & & & $\begin{array}{l}\text { Income variable not recoded, cannot guess how they would have } \\
\text { recoded it }\end{array}$ & Mistake & & No \\
\hline 41 & & & & & & & Used a different country as the reference dummy category & Mistake & $\begin{array}{l}\text { They specifically } \\
\text { stated in their notes } \\
\text { that the original study } \\
\text { did not mention which } \\
\text { dummy variable it } \\
\text { used, but it was in the } \\
\text { code }\end{array}$ & No \\
\hline 42 & $100 \%$ & $100 \%$ & 0.00 & $100 \%$ & $100 \%$ & 0.00 & & & & \\
\hline 44 & $100 \%$ & $100 \%$ & 0.00 & $100 \%$ & $100 \%$ & 0.00 & & & & \\
\hline 45 & $98 \%$ & $88 \%$ & 0.01 & $98 \%$ & $88 \%$ & 0.01 & $\begin{array}{l}\text { Control variable local not defined in submitted code, thus year } \\
\text { dummies were left out of analysis }\end{array}$ & Mistake & $\begin{array}{l}\text { Unclear if or how they } \\
\text { would have set up } \\
\text { their local differently }\end{array}$ & No \\
\hline
\end{tabular}


Table 5 Continued. Qualitative Categorization of Inter-Researcher Error

\begin{tabular}{|c|c|c|c|c|c|c|c|c|c|c|}
\hline \multirow[b]{2}{*}{ ID } & \multicolumn{3}{|c|}{$\underline{\text { Raw Results }}$} & \multicolumn{3}{|c|}{$\underline{\text { Curated Results }}$} & \multirow[b]{2}{*}{ Sources of Error } & \multirow[b]{2}{*}{ Category } & \multirow[b]{2}{*}{ Notes } & \multirow[b]{2}{*}{$\begin{array}{l}\text { Counter- } \\
\text { factual? }\end{array}$} \\
\hline & Verif. & Exact. & R.Error & Verif. & Exact. & R.Error & & & & \\
\hline 47 & $100 \%$ & $100 \%$ & 0.00 & $100 \%$ & $100 \%$ & 0.00 & & & & \\
\hline 48 & $81 \%$ & $46 \%$ & 0.04 & $81 \%$ & $46 \%$ & 0.04 & Recode variation A (employment) & $\begin{array}{l}\text { Mistake- } \\
\text { Procedural }\end{array}$ & & No \\
\hline 48 & & & & & & & $\begin{array}{l}\text { 'Self-employed' recoded to zero if 'not in LF' or 'unemployed' } \\
\text { scored for employment }\end{array}$ & $\begin{array}{l}\text { Mistake- } \\
\text { Procedural }\end{array}$ & & No \\
\hline 53 & $81 \%$ & $15 \%$ & 0.07 & $100 \%$ & $98 \%$ & 0.00 & $\begin{array}{l}\text { Recoded roughly } 6 \text { thousand cases to missing via the self- } \\
\text { employment variable recode }\end{array}$ & Mistake & & Yes \\
\hline \multicolumn{11}{|l|}{53} \\
\hline 56 & $100 \%$ & $69 \%$ & 0.01 & $100 \%$ & $69 \%$ & 0.01 & $\begin{array}{l}\text { Coded cases as missing rather than } 0 \text { when constructing } \\
\text { dichotomous variables resulting in roughly } 4 \mathrm{k} \text { less cases in the } \\
\text { analyzed data }\end{array}$ & $\begin{array}{l}\text { Mistake- } \\
\text { Procedural }\end{array}$ & & No \\
\hline 60 & $92 \%$ & $17 \%$ & 0.03 & $90 \%$ & $42 \%$ & 0.03 & Included additional independent variables & Mistake & & Yes \\
\hline 61 & $100 \%$ & $100 \%$ & 0.00 & $100 \%$ & $100 \%$ & 0.00 & & & & \\
\hline 63 & $100 \%$ & $100 \%$ & 0.00 & $100 \%$ & $100 \%$ & 0.00 & & & & \\
\hline 64 & $100 \%$ & $100 \%$ & 0.00 & $100 \%$ & $100 \%$ & 0.00 & & & & \\
\hline 65 & $73 \%$ & $19 \%$ & 0.04 & $100 \%$ & $71 \%$ & 0.01 & Forgot 2006 wave dummy & Mistake & & Yes \\
\hline 66 & $88 \%$ & $13 \%$ & 0.04 & $85 \%$ & $19 \%$ & 0.04 & Listwise deletion by all DVs & Procedural & $\begin{array}{l}\text { They could identify by } \\
\text { the case numbers or } \\
\text { code from the original } \\
\text { study that this is not } \\
\text { what was done, but } \\
\text { this is not clearly a } \\
\text { mistake as it could be } \\
\text { seen as a best } \\
\text { practice or procedural } \\
\text { step }\end{array}$ & No \\
\hline 66 & & & & & & & Did not recode nor include any individual level control variables & Mistake & $\begin{array}{l}\text { Unclear how the team } \\
\text { would have done the } \\
\text { recodes otherwise }\end{array}$ & No \\
\hline 66 & & & & & & & Included a respondent ID variable as a random-intercept & Mistake & & Yes \\
\hline 66 & & & & & & & One country left out of analysis & Mistake & & Yes \\
\hline 70 & $100 \%$ & $100 \%$ & 0.00 & $100 \%$ & $100 \%$ & 0.00 & & & & \\
\hline 71 & $100 \%$ & $100 \%$ & 0.00 & $100 \%$ & $100 \%$ & 0.00 & & & & \\
\hline
\end{tabular}


Table 5 Continued. Qualitative Categorization of Inter-Researcher Error

\begin{tabular}{|c|c|c|c|c|c|c|c|c|c|c|}
\hline \multirow[b]{2}{*}{ ID } & \multicolumn{3}{|c|}{$\underline{\text { Raw Results }}$} & \multicolumn{3}{|c|}{$\underline{\text { Curated Results }}$} & \multirow[b]{2}{*}{ Sources of Error } & \multirow[b]{2}{*}{ Category } & \multirow[b]{2}{*}{ Notes } & \multirow[b]{2}{*}{$\begin{array}{l}\text { Counter- } \\
\text { factual? }\end{array}$} \\
\hline & Verif. & Exact. & R.Error & Verif. & Exact. & R.Error & & & & \\
\hline 72 & $100 \%$ & $58 \%$ & 0.01 & $100 \%$ & $58 \%$ & 0.01 & Recode variation K (employment) & $\begin{array}{l}\text { Mistake- } \\
\text { Procedural }\end{array}$ & & No \\
\hline 72 & & & & & & & $\begin{array}{l}\text { Used a slightly different by-country income standardization } \\
\text { procedure }\end{array}$ & Procedural & & No \\
\hline 73 & $100 \%$ & $100 \%$ & 0.00 & $100 \%$ & $100 \%$ & 0.00 & & & & \\
\hline 76 & $100 \%$ & $96 \%$ & 0.00 & $100 \%$ & $96 \%$ & 0.00 & & & & \\
\hline 78 & $100 \%$ & $100 \%$ & 0.00 & $100 \%$ & $100 \%$ & 0.00 & & & & \\
\hline 82 & $100 \%$ & $100 \%$ & 0.00 & $100 \%$ & $100 \%$ & 0.00 & & & & \\
\hline
\end{tabular}

Table 5 Continued. Qualitative Categorization of Inter-Researcher Error

\begin{tabular}{|c|c|c|c|c|c|c|c|c|c|c|}
\hline \multirow[b]{2}{*}{ ID } & \multicolumn{3}{|c|}{ Raw Results } & \multicolumn{3}{|c|}{ Curated Results } & \multirow[b]{2}{*}{ Sources of Error } & \multirow[b]{2}{*}{ Category } & \multirow[b]{2}{*}{ Notes } & \multirow[b]{2}{*}{$\begin{array}{l}\text { Counter- } \\
\text { factual? }\end{array}$} \\
\hline & Verif. & Exact. & R.Error & Verif. & Exact. & R.Error & & & & \\
\hline 1 & $100 \%$ & $100 \%$ & 0.00 & $100 \%$ & $100 \%$ & 0.00 & Recode variation A (employment) & Procedural & & No \\
\hline 4 & $100 \%$ & $65 \%$ & 0.01 & $100 \%$ & $65 \%$ & 0.01 & Listwise deletion by all DVs & Procedural & & No \\
\hline 4 & & & & & & & Recode variation B \& C (education) & Procedural & & No \\
\hline 5 & $33 \%$ & $10 \%$ & 0.09 & $100 \%$ & $80 \%$ & 0.01 & Reverse coded 1996 and 2006 as wave indicators & Mistake & & Yes \\
\hline 5 & & & & & & & Recode variation A (employment) & Procedural & & No \\
\hline 5 & & & & & & & Recode variation B (education) & Procedural & & No \\
\hline 6 & $100 \%$ & $53 \%$ & 0.01 & $100 \%$ & $53 \%$ & 0.01 & Recode variation B (education) & Procedural & & No \\
\hline 6 & & & & & & & Recode variation A (employment) & Procedural & & No \\
\hline 7 & $92 \%$ & $46 \%$ & 0.04 & $92 \%$ & $46 \%$ & 0.04 & Recode variation D (employment) & Procedural & & No \\
\hline 7 & & & & & & & Recode variation B (education) & Procedural & & No \\
\hline 8 & $100 \%$ & $55 \%$ & 0.01 & $100 \%$ & $55 \%$ & 0.01 & Recode variation $\mathrm{H}$ (education) & Procedural & & No \\
\hline 8 & & & & & & & Recode variation A (employment) & Procedural & & No \\
\hline 11 & $90 \%$ & $55 \%$ & 0.02 & $90 \%$ & $55 \%$ & 0.02 & Recode variation B (education) & Procedural & & No \\
\hline
\end{tabular}


Table 5 Continued. Qualitative Categorization of Inter-Researcher Error

\begin{tabular}{|c|c|c|c|c|c|c|c|c|c|c|}
\hline \multirow[b]{2}{*}{ ID } & \multicolumn{3}{|c|}{$\underline{\text { Raw Results }}$} & \multicolumn{3}{|c|}{$\underline{\text { Curated Results }}$} & \multirow[b]{2}{*}{ Sources of Error } & \multirow[b]{2}{*}{ Category } & \multirow[b]{2}{*}{ Notes } & \multirow[b]{2}{*}{$\begin{array}{l}\text { Counter- } \\
\text { factual? }\end{array}$} \\
\hline & Verif. & Exact. & R.Error & Verif. & Exact. & R.Error & & & & \\
\hline 12 & $80 \%$ & $10 \%$ & 0.06 & $80 \%$ & $10 \%$ & 0.06 & Included N.Ireland as part of "United Kingdom" & Procedural & & No \\
\hline 12 & & & & & & & $\begin{array}{l}\text { Used a different } 13 \text { country-sample based on data availability at } \\
\text { the country-level and highest } 13 \text { scores on the social spending } \\
\text { indicator, rather than select based on the individual-level data. In } \\
\text { the end this led to an unbalanced time-series with some of the } 13 \\
\text { countries having only one case in either } 1996 \text { or } 2006 \text {. }\end{array}$ & Interpretational & $\begin{array}{l}\text { Instructions were not } \\
100 \% \text { clear on } \\
\text { whether to exclude } \\
\text { country cases based } \\
\text { on individual or } \\
\text { country-level data }\end{array}$ & No \\
\hline 12 & & & & & & & Recode variation E, F \& G (employment) & Procedural & & No \\
\hline 13 & $100 \%$ & $80 \%$ & 0.01 & $100 \%$ & $80 \%$ & 0.01 & Recode variation B \& C (education) & Procedural & & No \\
\hline 14 & $100 \%$ & $50 \%$ & 0.01 & $100 \%$ & $50 \%$ & 0.01 & Listwise deletion all DVs & Procedural & & No \\
\hline 18 & $100 \%$ & $80 \%$ & 0.01 & $100 \%$ & $80 \%$ & 0.01 & Recode variation $\mathrm{H}$ (education) & Procedural & & No \\
\hline 18 & & & & & & & Recode variation A (employment) & Procedural & & No \\
\hline 20 & $88 \%$ & $50 \%$ & 0.02 & $88 \%$ & $50 \%$ & 0.02 & Listwise deletion by all DVs & Procedural & & No \\
\hline 20 & & & & & & & Recode variation $\mathrm{A}$ (employment) & Procedural & & No \\
\hline 20 & & & & & & & $\begin{array}{l}\text { Recode variation B (education), plus coded missing for those with } \\
\text { 'none' on education who were a 'student' in the employment } \\
\text { variable }\end{array}$ & Procedural & & No \\
\hline 22 & $100 \%$ & $78 \%$ & 0.01 & $100 \%$ & $78 \%$ & 0.01 & $\begin{array}{l}\text { Employment and education variables left in original category } \\
\text { coding (not recoded) }\end{array}$ & Mistake & $\begin{array}{l}\text { Unclear how they } \\
\text { would have recoded } \\
\text { otherwise }\end{array}$ & No \\
\hline 23 & $100 \%$ & $80 \%$ & 0.01 & $100 \%$ & $80 \%$ & 0.01 & Recode variation B \& C (education) & Procedural & & No \\
\hline 23 & & & & & & & $\begin{array}{l}\text { Recode variation A (employment), and, 'less-than part time' also } \\
\text { coded 'not in labor force }\end{array}$ & Procedural & & No \\
\hline 24 & $100 \%$ & $75 \%$ & 0.01 & $100 \%$ & $75 \%$ & 0.01 & $\begin{array}{l}\text { Recode variation A (employment), and, 'less-than part time' also } \\
\text { coded 'not in labor force }\end{array}$ & Procedural & & No \\
\hline 26 & $100 \%$ & $58 \%$ & 0.01 & $100 \%$ & $58 \%$ & 0.01 & Used robust estimation routine & $\begin{array}{l}\text { Mistake- } \\
\text { Procedural }\end{array}$ & $\begin{array}{l}\text { Robust estimation not } \\
\text { mentioned in methods } \\
\text { description, but could } \\
\text { be a reasonable } \\
\text { assumption given the } \\
\text { type of model }\end{array}$ & No \\
\hline 26 & & & & & & & $\begin{array}{l}\text { Combined information from 'years of education' variable to create } \\
\text { 'primary or less' education variable }\end{array}$ & Procedural & & No \\
\hline 26 & & & & & & & Recode variation $\mathrm{A}$ (employment) & Procedural & & No \\
\hline
\end{tabular}


Table 5 Continued. Qualitative Categorization of Inter-Researcher Error

\begin{tabular}{|c|c|c|c|c|c|c|c|c|c|c|}
\hline \multirow[b]{2}{*}{ ID } & \multicolumn{3}{|c|}{$\underline{\text { Raw Results }}$} & \multicolumn{3}{|c|}{$\underline{\text { Curated Results }}$} & \multirow[b]{2}{*}{ Sources of Error } & \multirow[b]{2}{*}{ Category } & \multirow[b]{2}{*}{ Notes } & \multirow[b]{2}{*}{$\begin{array}{l}\text { Counter- } \\
\text { factual? }\end{array}$} \\
\hline & Verif. & Exact. & R.Error & Verif. & Exact. & R.Error & & & & \\
\hline 27 & $43 \%$ & $13 \%$ & 0.16 & $43 \%$ & $13 \%$ & 0.16 & $\begin{array}{l}\text { Merging of waves done with point-and-click in SPSS, education } \\
\text { variable recode not clear but may blur different coding schemes } \\
\text { between the two waves }\end{array}$ & $\begin{array}{l}\text { Mistake- } \\
\text { Procedural }\end{array}$ & $\begin{array}{l}\text { Missing parts of } \\
\text { workflow }\end{array}$ & No \\
\hline 28 & $95 \%$ & $83 \%$ & 0.01 & $95 \%$ & $83 \%$ & 0.01 & Centered age and all country-level variables & Interpretational & $\begin{array}{l}\text { Not mentioned in } \\
\text { Methods Section but } \\
\text { plausible choice given } \\
\text { the data and goals }\end{array}$ & No \\
\hline 28 & & & & & & & Used robust clustered SEs & $\begin{array}{l}\text { Mistake- } \\
\text { Procedural }\end{array}$ & $\begin{array}{l}\text { Robust estimation not } \\
\text { mentioned in Methods } \\
\text { Section, but could be } \\
\text { a reasonable } \\
\text { assumption given the } \\
\text { type of model }\end{array}$ & No \\
\hline 30 & $100 \%$ & $38 \%$ & 0.03 & $100 \%$ & $38 \%$ & 0.03 & $\begin{array}{l}\text { Recode variation A (employment), and, 'less-than part time' also } \\
\text { coded 'not in labor force }\end{array}$ & Procedural & & No \\
\hline 30 & & & & & & & Listwise deletion by all DVs & Procedural & & No \\
\hline 30 & & & & & & & Software accuracy & Procedural & $\begin{array}{l}\text { Some variables' } \\
\text { values had to be } \\
\text { truncated because } \\
\text { they were otherwise } \\
\text { too precise for MLWin }\end{array}$ & No \\
\hline 32 & $100 \%$ & $48 \%$ & 0.02 & $100 \%$ & $48 \%$ & 0.02 & Recode variation B \& C (education) & Procedural & & No \\
\hline 32 & & & & & & & Used robust clustered SEs & $\begin{array}{l}\text { Mistake- } \\
\text { Procedural }\end{array}$ & $\begin{array}{l}\text { Robust estimation not } \\
\text { mentioned in Methods } \\
\text { Section, but could be } \\
\text { a reasonable } \\
\text { assumption given the } \\
\text { type of model }\end{array}$ & No \\
\hline 33 & $100 \%$ & $53 \%$ & 0.01 & $100 \%$ & $53 \%$ & 0.01 & Recode variation $\mathrm{H}$ (education) & Procedural & & No \\
\hline 33 & & & & & & & Recode variation A (education) & Procedural & & No \\
\hline 35 & $93 \%$ & $40 \%$ & 0.02 & $93 \%$ & $40 \%$ & 0.02 & Recode variation B \& C (education) & Procedural & & No \\
\hline 35 & & & & & & & Recode variation $\mathrm{E}, \mathrm{F} \& \mathrm{G}$ (employment) & Procedural & & No \\
\hline
\end{tabular}


Table 5 Continued. Qualitative Categorization of Inter-Researcher Error

\begin{tabular}{|c|c|c|c|c|c|c|c|c|c|c|}
\hline \multirow[b]{2}{*}{ ID } & \multicolumn{3}{|c|}{$\underline{\text { Raw Results }}$} & \multicolumn{3}{|c|}{$\underline{\text { Curated Results }}$} & \multirow[b]{2}{*}{ Sources of Error } & \multirow[b]{2}{*}{ Category } & \multirow[b]{2}{*}{ Notes } & \multirow{2}{*}{$\begin{array}{l}\text { Counter- } \\
\text { factual? }\end{array}$} \\
\hline & Verif. & Exact. & R.Error & Verif. & Exact. & R.Error & & & & \\
\hline 43 & $100 \%$ & $45 \%$ & 0.01 & $100 \%$ & $45 \%$ & 0.01 & $\begin{array}{l}\text { Recoded 'incomplete primary' and 'primary complete' as } \\
\text { 'secondary' }\end{array}$ & Mistake & $\begin{array}{l}\text { We hesitated to } \\
\text { correct this given that } \\
\text { so many other teams } \\
\text { made so many } \\
\text { different choices in } \\
\text { this recode }\end{array}$ & No \\
\hline 43 & & & & & & & Recode variation A (employment) & Procedural & & No \\
\hline 46 & $100 \%$ & $43 \%$ & 0.01 & $100 \%$ & $43 \%$ & 0.01 & Recode variation B \& C (education) & Procedural & & No \\
\hline 46 & & & & & & & Recode variation A (employment) & Procedural & & No \\
\hline 46 & & & & & & & Used robust clustered SEs & $\begin{array}{l}\text { Mistake- } \\
\text { Procedural }\end{array}$ & $\begin{array}{l}\text { Robust estimation not } \\
\text { mentioned in Methods } \\
\text { Section, but could be } \\
\text { a reasonable } \\
\text { assumption given the } \\
\text { type of model }\end{array}$ & No \\
\hline 49 & $100 \%$ & $100 \%$ & 0.00 & $100 \%$ & $100 \%$ & 0.00 & & & & \\
\hline 50 & $100 \%$ & $28 \%$ & 0.02 & $100 \%$ & $28 \%$ & 0.02 & Recode variation B (education) & Procedural & & No \\
\hline 50 & & & & & & & $\begin{array}{l}\text { Merging process resulting in only } 12 \text { countries, mislabeled cases } \\
\text { and thus introduced 6,000 extra cases. }\end{array}$ & Mistake & $\begin{array}{l}\text { Curation would require } \\
\text { writing nearly new } \\
\text { code, requiring us to } \\
\text { make too many } \\
\text { assumptions about } \\
\text { what they would have } \\
\text { done }\end{array}$ & No \\
\hline 51 & $63 \%$ & $13 \%$ & 0.16 & $63 \%$ & $13 \%$ & 0.16 & $\begin{array}{l}\text { Using Stata for the first time, ran multilevel logit models. Did } \\
\text { coding of data without saving, not reproducible or curatable. }\end{array}$ & Mistake & $\begin{array}{l}\text { Missing parts of } \\
\text { workflow; questionable } \\
\text { methodological } \\
\text { competencies }\end{array}$ & No \\
\hline 52 & $90 \%$ & $25 \%$ & 0.02 & $100 \%$ & $100 \%$ & 0.00 & Dropped Spain but included Russia & Mistake & & Yes \\
\hline 52 & & & & & & & $\begin{array}{l}\text { Reported two decimal places (therefore, only two decimal places } \\
\text { were kept after counterfactual) }\end{array}$ & Procedural & & No \\
\hline 52 & & & & & & & Centered age & Interpretational & $\begin{array}{l}\text { Not mentioned in } \\
\text { Methods Section but } \\
\text { plausible choice given } \\
\text { data and goals }\end{array}$ & No \\
\hline 52 & & & & & & & 'Helping family member' coded as 'unemployed' & Procedural & & No \\
\hline
\end{tabular}




\section{Table 5 Continued. Qualitative Categorization of Inter-Researcher Error}

\begin{tabular}{|c|c|c|c|c|c|c|c|c|c|c|}
\hline \multirow[b]{2}{*}{ ID } & \multicolumn{3}{|c|}{$\underline{\text { Raw Results }}$} & \multicolumn{3}{|c|}{$\underline{\text { Curated Results }}$} & \multirow[b]{2}{*}{ Sources of Error } & \multirow[b]{2}{*}{ Category } & \multirow[b]{2}{*}{ Notes } & \multirow[b]{2}{*}{$\begin{array}{l}\text { Counter- } \\
\text { factual? }\end{array}$} \\
\hline & Verif. & Exact. & R.Error & Verif. & Exact. & R.Error & & & & \\
\hline 54 & $100 \%$ & $53 \%$ & 0.01 & $100 \%$ & $53 \%$ & 0.01 & Recode variation B (education) & Procedural & & No \\
\hline 54 & & & & & & & Introduced roughly 6,000 cases by recoding missing to zero & Mistake & $\begin{array}{l}\text { Unclear from code } \\
\text { how they would have } \\
\text { done it differently }\end{array}$ & No \\
\hline 55 & $100 \%$ & $80 \%$ & 0.01 & $100 \%$ & $80 \%$ & 0.01 & Coded missing for those with 'none' on education & $\begin{array}{l}\text { Mistake- } \\
\text { Procedural }\end{array}$ & $\begin{array}{l}\text { Plausible to drop } \\
\text { these cases }\end{array}$ & No \\
\hline 57 & $100 \%$ & $80 \%$ & 0.01 & $100 \%$ & $80 \%$ & 0.01 & Recode variation $B$ \& C (education) & Procedural & & No \\
\hline 57 & & & & & & & Listwise deletion on all analytical variables & Procedural & & \\
\hline 58 & $100 \%$ & $80 \%$ & 0.01 & $100 \%$ & $80 \%$ & 0.01 & Recode variation B \& C (education) & Procedural & & No \\
\hline 59 & $40 \%$ & $8 \%$ & 0.13 & $40 \%$ & $8 \%$ & 0.13 & $\begin{array}{l}\text { Analyzed the two waves of data (1996 \& 2006) separately, results } \\
\text { are an average }\end{array}$ & Mistake & $\begin{array}{l}\text { Questionable } \\
\text { methodoological } \\
\text { competencies }\end{array}$ & No \\
\hline 62 & $98 \%$ & $38 \%$ & 0.02 & $98 \%$ & $38 \%$ & 0.02 & Parts of code missing & Procedural & $\begin{array}{l}\text { Missing parts of } \\
\text { workflow }\end{array}$ & No \\
\hline 67 & $60 \%$ & $0 \%$ & 0.16 & $58 \%$ & $20 \%$ & 0.05 & All DVs for 2006 wave coded 0 & Mistake & & Yes \\
\hline 68 & $98 \%$ & $43 \%$ & 0.02 & $98 \%$ & $43 \%$ & 0.02 & Recode variation $\mathrm{H}$ (education) & Procedural & & No \\
\hline 68 & & & & & & & $\begin{array}{l}\text { 'secondary completion' recoded to 'primary' in education variable, it } \\
\text { appears the team used } 2 \text { through } 8 \text { rather than } 1 \text { through } 7 \text { to } \\
\text { make their recodes; same for employment variable } 2 \text { through } 11\end{array}$ & $\begin{array}{l}\text { Mistake- } \\
\text { Procedural }\end{array}$ & $\begin{array}{l}\text { Not clear how they } \\
\text { would have done it } \\
\text { differently }\end{array}$ & No \\
\hline 68 & & & & & & & Rounded output to two-decimal places & Procedural & & No \\
\hline 69 & $85 \%$ & $18 \%$ & 0.03 & $100 \%$ & $95 \%$ & 0.00 & Recoded DV missing values to zero & Mistake & & Yes \\
\hline 69 & & & & & & & Recode variation A (employment) & Procedural & & No \\
\hline 74 & $85 \%$ & $15 \%$ & 0.04 & $85 \%$ & $15 \%$ & 0.04 & Used multilevel models instead of 'two-way fixed effects' & Mistake & $\begin{array}{l}\text { Counterfactual not } \\
\text { possible as it would } \\
\text { require new coding } \\
\text { with a different } \\
\text { package or equation }\end{array}$ & No \\
\hline 74 & & & & & & & Recode variation $\mathrm{D}$ (employment) & Procedural & & No \\
\hline 75 & $98 \%$ & $45 \%$ & 0.02 & $98 \%$ & $45 \%$ & 0.02 & Recode variation B \& C (education) & Procedural & & No \\
\hline 75 & & & & & & & Used maximum likelihood estimation & Procedural & $\begin{array}{l}\text { The estimator was not } \\
\text { clearly defined, but } \\
\text { implied from the } \\
\text { description }\end{array}$ & No \\
\hline
\end{tabular}


Table 5 Continued. Qualitative Categorization of Inter-Researcher Error

\begin{tabular}{|c|c|c|c|c|c|c|c|c|c|c|}
\hline \multirow[b]{2}{*}{ ID } & \multicolumn{3}{|c|}{$\underline{\text { Raw Results }}$} & \multicolumn{3}{|c|}{$\underline{\text { Curated Results }}$} & \multirow[b]{2}{*}{ Sources of Error } & \multirow[b]{2}{*}{ Category } & \multirow[b]{2}{*}{ Notes } & \multirow[b]{2}{*}{$\begin{array}{l}\text { Counter- } \\
\text { factual? }\end{array}$} \\
\hline & Verif. & Exact. & R.Error & Verif. & Exact. & R.Error & & & & \\
\hline 77 & $73 \%$ & $0 \%$ & 0.99 & $100 \%$ & $63 \%$ & 0.01 & Reported logit coefficients instead of odds ratios & Mistake & & Yes \\
\hline 77 & & & & & & & Recode variation $\mathrm{H}$ (education) & Procedural & & No \\
\hline 77 & & & & & & & Clustered SEs by country & $\begin{array}{l}\text { Mistake- } \\
\text { Procedural }\end{array}$ & $\begin{array}{l}\text { Robust estimation not } \\
\text { mentioned in methods } \\
\text { description, but could } \\
\text { be a reasonable } \\
\text { assumption given the } \\
\text { type of model }\end{array}$ & No \\
\hline 79 & $100 \%$ & $95 \%$ & 0.00 & $100 \%$ & $95 \%$ & 0.00 & & & & \\
\hline 80 & $73 \%$ & $5 \%$ & 0.95 & $100 \%$ & $100 \%$ & 0.00 & Reported logit coefficients instead of odds ratios & Mistake & & Yes \\
\hline 81 & $53 \%$ & $5 \%$ & 0.12 & $53 \%$ & $5 \%$ & 0.12 & $\begin{array}{l}\text { Analyzed the two waves of data (1996 \& 2006) separately, results } \\
\text { are taken as the average }\end{array}$ & Mistake & $\begin{array}{l}\text { Questionable } \\
\text { methodological } \\
\text { competencies }\end{array}$ & No \\
\hline 83 & $100 \%$ & $73 \%$ & 0.01 & $100 \%$ & $73 \%$ & 0.01 & $\begin{array}{l}\text { 'less than part-time' coded as 'not in labor force' for employment } \\
\text { category }\end{array}$ & $\begin{array}{l}\text { Mistake- } \\
\text { Procedural }\end{array}$ & & No \\
\hline 83 & & & & & & & Recode variation C (education) & Procedural & & No \\
\hline 84 & $100 \%$ & $85 \%$ & 0.01 & $100 \%$ & $85 \%$ & 0.01 & $\begin{array}{l}\text { Recoded education into only two, 'primary or less' and 'secondary } \\
\text { or more' }\end{array}$ & Mistake & $\begin{array}{l}\text { The description was } \\
\text { clear on this, but we } \\
\text { do not have a } \\
\text { counterfactual }\end{array}$ & No \\
\hline 84 & & & & & & & $\begin{array}{l}\text { 'helping family member', 'housewife/-man, home maker', and 'less } \\
\text { than part-time' coded as unemployed; and 'Other/not in labor force' } \\
\text { coded as missing }\end{array}$ & $\begin{array}{l}\text { Mistake- } \\
\text { Procedural }\end{array}$ & $\begin{array}{l}\text { Could arge that these } \\
\text { are plausible steps } \\
\text { given the ambiguities } \\
\text { in the methods } \\
\text { description }\end{array}$ & No \\
\hline 85 & $100 \%$ & $78 \%$ & 0.01 & $100 \%$ & $78 \%$ & 0.01 & Recode variation B \& C (education) & Procedural & & No \\
\hline 85 & & & & & & & $\begin{array}{l}\text { 'helping family member', 'housewife/-man, home maker', and 'less } \\
\text { than part-time' coded as unemployed }\end{array}$ & Procedural & & No \\
\hline
\end{tabular}


Table 9. Correlations by Group. Team-Level N = 85

\begin{tabular}{|c|c|c|c|c|c|c|c|c|c|c|c|c|c|c|c|c|c|}
\hline & Variable & 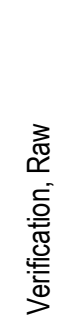 & 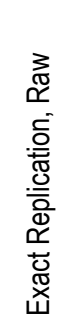 & 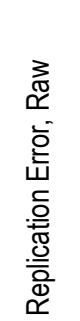 & 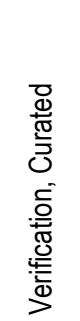 & 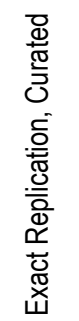 & 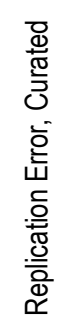 & $\frac{\pi}{\frac{\pi}{\pi}}$ & 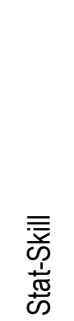 & $\begin{array}{l}\text { 䓂 } \\
\text { 董 }\end{array}$ & $\begin{array}{l}\text { 흥 } \\
\text { 응 } \\
\text { க }\end{array}$ & 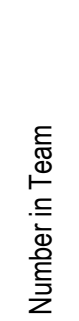 & 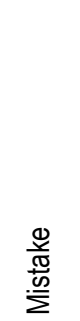 & 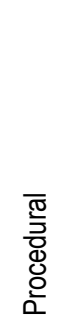 & 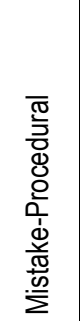 & 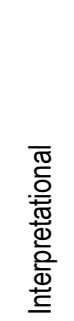 & 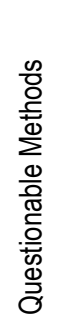 \\
\hline \multirow{16}{*}{ 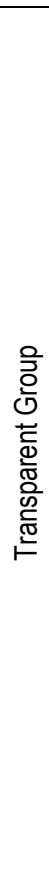 } & Verif & 1.00 & & & & & & & & & & & & & & & \\
\hline & Exact Rep & 0.73 & 1.00 & & & & & & & & & & & & & & \\
\hline & Rep Error & -0.84 & -0.86 & 1.00 & & & & & & & & & & & & & \\
\hline & Verif, C & $\mathrm{NA}$ & NA & $\mathrm{NA}$ & 1.00 & & & & & & & & & & & & \\
\hline & Exact Rep, C & $\mathrm{NA}$ & NA & $\mathrm{NA}$ & 0.71 & 1.00 & & & & & & & & & & & \\
\hline & Rep Error, C & NA & NA & $\mathrm{NA}$ & -0.84 & -0.89 & 1.00 & & & & & & & & & & \\
\hline & Stata & 0.04 & 0.25 & -0.19 & 0.36 & 0.37 & -0.38 & 1.00 & & & & & & & & & \\
\hline & Stat-Skill & -0.21 & -0.14 & 0.17 & -0.17 & -0.19 & 0.19 & 0.06 & 1.00 & & & & & & & & \\
\hline & Difficult & 0.01 & -0.22 & 0.14 & -0.22 & -0.28 & 0.27 & -0.17 & -0.31 & 1.00 & & & & & & & \\
\hline & Sociology & 0.13 & 0.14 & -0.15 & 0.19 & 0.08 & -0.09 & 0.36 & -0.03 & -0.14 & 1.00 & & & & & & \\
\hline & \# in Team & -0.16 & -0.06 & 0.06 & -0.24 & -0.15 & 0.19 & 0.02 & -0.11 & -0.30 & 0.14 & 1.00 & & & & & \\
\hline & Mistake & -0.65 & -0.73 & 0.78 & -0.50 & -0.78 & 0.76 & -0.38 & 0.13 & 0.29 & -0.19 & 0.07 & 1.00 & & & & \\
\hline & Procedural & -0.13 & -0.54 & 0.34 & -0.21 & -0.43 & 0.30 & -0.17 & -0.12 & 0.28 & -0.04 & 0.02 & 0.27 & 1.00 & & & \\
\hline & Mistake-Pr. & -0.33 & -0.48 & 0.44 & -0.05 & -0.31 & 0.23 & 0.17 & 0.29 & 0.03 & 0.17 & 0.09 & 0.04 & 0.42 & 1.00 & & \\
\hline & Interpret. & NA & NA & NA & NA & NA & NA & NA & NA & NA & NA & NA & NA & $\mathrm{NA}$ & NA & NA & \\
\hline & Questionable & NA & NA & NA & NA & $\mathrm{NA}$ & NA & NA & NA & NA & NA & NA & NA & $\mathrm{NA}$ & $\mathrm{NA}$ & NA & $\mathrm{NA}$ \\
\hline \multirow{16}{*}{ 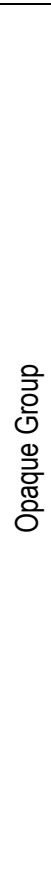 } & Verif & 1.00 & & & & & & & & & & & & & & & \\
\hline & Exact Rep & 0.70 & 1.00 & & & & & & & & & & & & & & \\
\hline & Rep Error & -0.92 & -0.73 & 1.00 & & & & & & & & & & & & & \\
\hline & Verif, C & $\mathrm{NA}$ & NA & $\mathrm{NA}$ & 1.00 & & & & & & & & & & & & \\
\hline & Exact Rep, C & NA & NA & $\mathrm{NA}$ & 0.73 & 1.00 & & & & & & & & & & & \\
\hline & Rep Error, C & NA & NA & NA & -0.40 & -0.49 & 1.00 & & & & & & & & & & \\
\hline & Stata & 0.22 & 0.23 & -0.16 & 0.11 & 0.17 & -0.09 & 1.00 & & & & & & & & & \\
\hline & Stat-Skill & 0.08 & 0.09 & -0.08 & 0.07 & 0.13 & -0.12 & 0.16 & 1.00 & & & & & & & & \\
\hline & Difficult & -0.54 & -0.46 & 0.60 & -0.37 & -0.39 & -0.03 & -0.39 & -0.29 & 1.00 & & & & & & & \\
\hline & Sociology & 0.14 & 0.19 & -0.17 & 0.04 & 0.17 & -0.03 & 0.59 & 0.37 & -0.41 & 1.00 & & & & & & \\
\hline & \# in Team & 0.09 & 0.26 & -0.16 & 0.10 & 0.28 & 0.04 & 0.18 & 0.04 & -0.41 & 0.26 & 1.00 & & & & & \\
\hline & Mistake & -0.27 & -0.15 & 0.23 & -0.49 & -0.57 & 0.39 & -0.14 & -0.25 & 0.41 & -0.14 & -0.28 & 1.00 & & & & \\
\hline & Procedural & 0.39 & -0.01 & -0.32 & 0.30 & 0.03 & -0.24 & 0.27 & 0.26 & -0.35 & 0.12 & 0.06 & -0.42 & 1.00 & & & \\
\hline & Mistake-Pr. & 0.01 & 0.01 & 0.01 & 0.02 & 0.06 & 0.14 & -0.03 & 0.01 & 0.02 & 0.00 & 0.18 & -0.14 & -0.18 & 1.00 & & \\
\hline & \begin{tabular}{|l} 
Interpret. \\
\end{tabular} & -0.03 & 0.06 & 0.00 & -0.03 & -0.09 & -0.05 & 0.02 & 0.32 & -0.07 & 0.26 & 0.03 & 0.00 & 0.04 & 0.07 & 1.00 & \\
\hline & Questionable & -0.65 & -0.49 & 0.73 & -0.51 & -0.38 & 0.08 & 0.02 & -0.19 & 0.45 & -0.09 & -0.20 & 0.38 & -0.36 & $\begin{array}{l}-0.14 \\
\end{array}$ & -0.07 & 1.00 \\
\hline
\end{tabular}


